\title{
THE TRANSMEMBRANE HEPARAN SULPHATE PROTEOGLYCAN SYNDECAN-4 IS INVOLVED IN ESTABLISHMENT OF THE LAMELLAR STRUCTURE OF THE ANNULUS FIBROSUS OF THE INTERVERTEBRAL DISC
}

\author{
M.C. Beckett, J.R. Ralphs, B. Caterson and A.J. Hayes* \\ Connective Tissue Biology Laboratory, Cardiff School of Biosciences and Cardiff Institute of Tissue Engineering and \\ Repair, Cardiff University, Cardiff, CF10 3AX, UK
}

\begin{abstract}
The annulus fibrosus of the intervertebral disc unites adjacent vertebral bodies along the length of the spine and provides tensile resistance towards compressive, twisting and bending movements arising through gait. It consists of a nested series of oriented collagenous lamellae, arranged in cross-ply circumferentially around the nucleus pulposus. The organisation of oriented collagen in the annulus is established during foetal development by an identical arrangement of oriented fibroblasts that are precisely organised into cell sheets, or laminae. These provide a template for ordered deposition of extracellular matrix material on cell surfaces, by means of a poorly understood mechanism involving the actin cytoskeleton. In this study, we investigate the role of two cell surface heparan sulphate proteoglycans (HSPGs), glypican-6 and syndecan-4, in the matrix assembly process in the developmental rat intervertebral disc. We compare their expression patterns with those of heparan sulphate and the interactive, cellsurface adhesive glycoprotein, fibronectin, and relate these to the stage-specific collagenous architectures present within the annulus at both light and electron microscopic levels. We show that both proteoglycans are strongly associated with the development, growth and aging of the intervertebral disc. Furthermore, the immunohistochemical labelling patterns suggest that syndecan-4, in particular, plays a potentially-significant role in annulus formation. We propose that this HSPG mediates interaction between the actin cytoskeleton and nascent extracellular matrix in the lamellar organisation of annulus tissue. These data add considerably towards an understanding of how cells organise and maintain complex, oriented extracellular matrices and has particular clinical relevance to the fields of tissue engineering and repair.
\end{abstract}

Keywords: Syndecan-4, glypican-6, heparan sulphate, collagen, annulus fibrosus, intervertebral disc.

*Address for correspondence:

Anthony J. Hayes

Bioimaging Unit

Cardiff School of Biosciences

Cardiff University

Cardiff CF10 3US, UK

Telephone Number: +44 (0)2920 876611

FAX Number: +44 (0)2920 874594

E-mail: hayesaj@cf.ac.uk

\section{Introduction}

Intervertebral discs (IVD) are fibrocartilaginous symphyses that unite adjacent vertebral bodies along the length of the spine. They comprise a gelatinous proteoglycan-rich core, the nucleus pulposus, surrounded by a thick, fibrous envelope of collagen known as the annulus fibrosus. The structure of the annulus is critical to the biomechanical function of the IVD in resisting compressive loads borne by the nucleus, whilst allowing limited twisting and bending movements of the spine. It consists of a nested series of highly ordered collagenous lamellae arranged circumferentially around the nucleus (Humzah and Soames, 1988). The outermost lamellae of the annulus are anchored within the bone of the vertebral bodies; but medially the lamellae arc inwards within the vertebral endplates thereby encapsulating the nucleus pulposus (Hayes et al., 2011b; Nosikova et al., 2012). Within individual lamellae, collagen fibres are arranged in parallel bundles that are inclined at a constant angle to the long axis of the vertebral column. In successive lamellae, the angle of fibre tilt is reversed so that every other lamella has the same collagen fibre orientation (Hashizume, 1980; Hickey and Hukins, 1980; Humzah and Soames, 1988). This crossply organisation of collagen confers considerable tensile strength to the annulus and is essential to normal IVD function in resisting complex biomechanical loads arising through gait and spinal muscle activity.

The cellular template of the annulus fibrosus is established during early foetal development through an elegant sequence of morphogenetic and cellular differentiation events. These occur at embryonic day 55 in the human (Peacock, 1951) and between embryonic days 15 and 16 in the rat (Rufai et al., 1995). As the chondrifying vertebral bodies of the foetal spine begin to enlarge, they exert compressive forces on the notochord causing it to constrict intravertebrally and swell intervertebrally, so that it bulges outwards into the surrounding disc primordia (Aszodi et al., 1998). The notochordal bulges give rise to the nucleus pulposus of the disc and appear to trigger overt differentiation of the surrounding mesenchymal tissue into annulus fibrosus (Aszodi et al., 1998). The inner part of the annulus, adjacent to the nucleus, develops into a cartilage-like tissue that is continuous with the hyaline cartilage of the developing vertebral bodies; whereas the outer fibroblastic part of the annulus becomes organised into highly oriented laminae. These laminae then lay down the oriented bundles of collagen that make up the functional lamellae of the mature outer annulus (Hayes et al., 2011b; Peacock, 1951; Rufai et al., 1995). 
Underlying the cellular template of the foetal outer annulus is an intracellular network of oriented actomyosin stress fibres coupled by adherens junctions (Hayes et al., 1999). These appear to facilitate the initial cellular orientation phase within the annulus and, together with focal adhesion complexes at the cell surface, control the organised deposition of extracellular matrix (ECM) (Hayes et al., 1999, 2001, 2011b). The cellular mechanisms underlying these developmental events are not fully understood; however, the matrix assembly process in the annulus appears similar to that occurring in other oriented connective tissues, e.g., tendon and cornea (Birk and Trelstad, 1984, 1986; Young et al., 2014) and may involve a similar panoply of extracellular regulatory molecules, that includes the FACIT collagens (Fibril-Associated Collagens with Interrupted Triple-helices) and SLRPs (Small Leucine-Rich Proteoglycans) (Banos et al., 2008; Hayes et al., 2011b; Sivan et al., 2013; Zhang et al., 2005).

The heparan sulphate proteoglycans (HSPG) are a diverse group of proteoglycans (PG) that function as key regulators of tissue morphogenesis and development (Lin, 2004). The HSPG include the multi-domain $\mathrm{ECM} /$ basement membrane PG perlecan, as well as the glypican and syndecan families that occur at the cell surface and are linked to the plasma membrane by a glycosylphosphatidylinositol (GPI) anchor or a transmembrane domain, respectively. Whilst perlecan has been shown to be a major interactive component of the developing spine and IVD (Melrose et al., 2003, 2008; Shu et al., 2013a, 2013b), far less is known of the roles that the syndecan and glypican families play in IVD development.

The syndecans have four family members (syndecans 1-4) that play diverse roles in signalling in a variety of vertebrate tissues by acting as receptors/co-receptors for a range of ECM molecules (e.g., collagens I, III, V, thrombospondin, vitronectin and fibronectin) and matrix growth factors (e.g., basic fibroblast growth factor (bFGF) and transforming growth factor- $\beta$ (TGF- $\beta$ )) (Bernfield and Sanderson, 1990; Carey, 1997; Choi et al., 2011). Family members carry heparan sulphate (HS) and/or chondroitin sulphate (CS) chains that contribute towards many of their interactive properties (Deepa et al., 2004; Horowitz et al., 2002; Lopes et al., 2006; Tumova et al., 2000). Syndecan-4 is the most well-studied and best understood member of the syndecan family. It plays a central role in modulating fibroblast cell adhesion at focal contacts and mediating interaction between the actin cytoskeleton and the ECM (Couchman and Woods, 1999; Echtermeyer et al., 1999; Morgan et al., 2007; Okina et al., 2012; Saoncella et al., 1999; Woods and Couchman, 1994, 2001). As such, syndecan-4 plays an important role in mechanotransduction through interaction with integrins and also through direct linkage with the ECM (Bellin et al., 2009).

The glypican family also play similar diverse signalling roles in morphogenesis, development and growth (Fico et al., 2011; Filmus et al., 2008; Yan and Lin, 2009). Unlike the syndecans, which can carry HS and CS GAG, the glypicans only carry HS chains. The glypican family comprises six members (glypicans 1-6) that serve as key regulators of several important signalling pathways, including Wnt and Hedgehog, as well as in FGF and bone morphogenetic protein (BMP) signalling (Filmus and Capurro, 2014). The glypicans are widely expressed during vertebrate development (Veugelers et al., 1999) with glypican-6, in particular, playing important roles in endochondral ossification and skeletal growth (CamposXavier et al., 2009). The importance of this HSPG in normal development is underlined by mutations of the GPC6 gene, which cause recessive omodysplasia, a disease characterised by shortened limbs, facial abnormalities and retarded skeletal development (Campos-Xavier et al., 2009; Veugelers et al., 1999).

In the present study we examine the distribution of syndecan- 4 and glypican- 6 in annulus formation and intervertebral disc ontogeny. We compare their expression patterns with that of heparan sulphate (both native HS chains and HS stub neoepitope) and the interactive cell surface glycoprotein fibronectin, and relate these to the stage-specific collagenous architectures present within the annulus at light and electron microscopic levels. We show that both HSPGs are associated with the ontogeny of the disc; however, syndecan-4 in particular appears to have significant involvement in the establishment of early annular lamellae during foetal disc development.

\section{Materials and Methods}

\section{Source of discal material}

White Wistar rats were killed humanely using a Schedule 1 procedure (Animals Scientific Procedures Act, 1986). Discal material was obtained from foetal stages (embryonic days 15-21), neonates, skeletally mature adults (4 months) and aged rats (24 months). Lumbar (L)1-L2 IVDs were dissected out of adult spines, whereas foetal and neonate spines were processed in situ (see below). Foetal and neonate discs were examined at all spinal levels; however, to facilitate direct comparison between ages and allow comparative analysis of labelling patterns, consecutive serial sections of the same L1-L2 IVD were photographed whenever possible.

\section{Wax histology}

Samples were fixed in $10 \%$ neutral buffered formol saline and decalcified (post-natal material only) in $2 \%$ nitric acid until radiologically clear. Tissues were then processed into paraffin wax using standard histological methods. $6 \mu \mathrm{m}$ serial sagittal sections were cut through the vertebral column/IVD and collected onto Histobond glass histology slides (R.A. Lamb/ThermoFisher, Loughborough, UK). Tissue sections were de-waxed and rehydrated prior to all staining and immunohistochemical labelling procedures. For routine histological observation, sections were labelled with Alcian blue, haematoxylin and eosin (H \& E) and photographed under bright-field optics. For polarising microscopy, sections were stained in $0.1 \%(\mathrm{w} / \mathrm{v})$ Sirius red $\mathrm{F} 3 \mathrm{~B}$ in saturated aqueous picric acid to augment collagen birefringence.

\section{Immunohistochemistry}

For immunohistochemistry, the following developmental stages were examined: E15, E17, E19, neonate, 4 
Table 1. Antibody details.

\begin{tabular}{|c|c|l|c|}
\hline $\begin{array}{c}\text { Antibody } \\
\text { (dilution) }\end{array}$ & $\begin{array}{c}\text { Species/clone } \\
\text { (isotype) }\end{array}$ & \multicolumn{1}{|c|}{ Specificity } & Source \\
\hline 10E4 (1:25) & $\begin{array}{c}\text { Mouse/mono } \\
\text { (IgM, } \kappa)\end{array}$ & $\begin{array}{l}\text { Antibody reacts with an epitope that includes a N-sulphated } \\
\text { glucosamine residue present in many types of native HS } \\
\text { chains }\end{array}$ & AMS biotechnology \\
\hline 3 G10 (1:50) & $\begin{array}{c}\text { Mouse/mono } \\
\text { (IgG2a, } \kappa)\end{array}$ & $\begin{array}{l}\text { Antibody reacts with the desaturated hexuronate } \\
\text { (glucoronate) present at the non-reducing terminus of all } \\
\text { heparatinase-generated HS stubs }\end{array}$ & AMS biotechnology \\
\hline SDC4 (1:100) & Rabbit/poly & $\begin{array}{l}\text { Antibody raised against a synthetic peptide surrounding } \\
\text { amino acid 184 of human syndecan-4 }\end{array}$ & Cell Sciences \\
\hline T20 (1:50) & $\begin{array}{c}\text { Rabbit/poly } \\
\text { (IgG) }\end{array}$ & $\begin{array}{l}\text { Antibody raised against a peptide mapping near the } \\
\text { C-terminus of glypican-6 of human origi }\end{array}$ & Santa Cruz Biotech \\
\hline FN (1:100) & Rabbit/poly & Affinity isolated against human fibronectin & Sigma \\
\hline
\end{tabular}

month and 24 months $(n=3)$. Dewaxed sections were immunohistochemically labelled using the Vector $\mathrm{ABC}$ universal immunoperoxidase labelling kit (Vector Laboratories, Burlingame, CA, USA) in conjunction with a panel of commercially-available antibodies towards heparan sulphate GAG (both native HS chains and HS stub neoepitope); syndecan-4; glypican-6 and fibronectin (refer to Table 1 for antibody details). Rehydrated tissue sections were first circumscribed with a Dako delimiting pen (Dako, Glostrup, Denmark) and treated with proteinase $\mathrm{K}$ antigen unmasking solution (DakoCytomation, Glostrup, Denmark) for $10 \mathrm{~min}$ at room temperature before washing in water. To generate the reactive delta- 4,5 uronate HS stub neoepitope recognised by $\mathrm{mAb} 3 \mathrm{G} 10$, tissue sections were treated with $5 \mathrm{mU} / \mathrm{mL}$ heparitinase in $50 \mathrm{mM}$ sodium acetate buffer ( $\mathrm{pH} 7.0$ ) containing $5 \mathrm{mM} \mathrm{CaCl}_{2}$ for $1 \mathrm{~h}$ at $37{ }^{\circ} \mathrm{C}$. Sections were then washed in water and immersed in $0.3 \%$ hydrogen peroxide $(\mathrm{v} / \mathrm{v})$ for $1 \mathrm{~h}$ to block endogenous peroxidase activity. After washing, sections were treated with normal horse-serum for $30 \mathrm{~min}$ to prevent non-specific antibody binding. Each of the antibodies were then applied to their respective tissue sections and incubated overnight at $4{ }^{\circ} \mathrm{C}$. Alongside these, the following control treatments were carried out: (1) to assess the level of non-specific binding of primary and secondary antibodies, tissue sections were incubated with either 'naïve' immunoglobulins, or the primary antibody was omitted and replaced with phosphate-buffered saline (PBS), $\mathrm{pH} 7.4$; (2) to validate the HS labelling patterns, the above heparitinase pre-digestion step was omitted for $\mathrm{mAb}$ 3G10 (which recognises a heparitinase-generated HS stub neoepitope) but included for $\mathrm{mAb} 10 \mathrm{E} 4$ (which recognises a native HS epitope). After overnight incubation, sections were washed in PBS followed by exposure to biotinylated secondary antibody for $30 \mathrm{~min}$ at room temperature. Sections were again washed and incubated with the avidin-biotin complex for $30 \mathrm{~min}$ before another wash step. NovaRed peroxidase substrate (Vector Laboratories, Peterborough, UK) was then added to the sections until the desired colour intensity was developed. Sections were again washed, counterstained with haematoxylin and then photographed under bright-field optics as described below.

\section{Light microscopy}

Representative regions of disc were imaged on a Leica DM6000 research microscope (Leica Microsystems, Heidelberg, Germany) equipped with a ProgRes C5 colour digital camera (Jenoptik, Jena, Germany). The extent of labelling in the constituent vertebral tissues for each developmental stage was graded as follows: +++ , strong labelling; ++, moderate labelling; +, weak labelling; -, absence of label. To facilitate direct spatio-temporal comparison of antibody labelling patterns, sequential sections of lumbar discs from representative age-matched samples (E15, pre-disc differentiation; E19, post-disc differentiation; 4 month, adult; and 24 month, aged) were depicted side-by-side in the assembled figures using Microsoft PowerPoint software.

\section{Electron microscopy}

Lumbar segments from E15, E16 and E19 foetuses and L1-2 IVDs from neonates, 4 month (adult) and 24 month (aged) animals were fixed in $2 \%$ glutaraldehyde and $2 \%$ paraformaldehyde in $0.1 \mathrm{M}$ cacodylate buffer $(\mathrm{pH}$ 7.4) for $2 \mathrm{~h}$ at $2{ }^{\circ} \mathrm{C}$. For transmission electron microscopy, samples were washed in buffer and then post-fixed in $1 \%$ osmium containing $1.5 \%$ potassium ferrocyanide (Sigma-Aldrich, St. Louis, MO, USA), to help retain PGs, for $1 \mathrm{~h}$ at room temperature. After washing, samples were stained en bloc with $2 \%$ uranyl acetate $(\mathrm{w} / \mathrm{v})$, dehydrated in ethanol, cleared in propylene oxide and infiltrated and embedded in Araldite resin. Semi-thin $(1 \mu \mathrm{m})$ resin sections, stained with $1 \%$ toluidine blue in borax, were used to localise areas of interest within the discal tissues. Ultrathin $(60 \mathrm{~nm})$ resin sections were then cut and stained with $2 \%$ uranyl acetate (w/v) and lead citrate before observation in a Phillips 208 transmission electron microscope (Phillips, Eindhoven, The Netherlands). For scanning electron microscopy, samples were washed in buffer, dehydrated in ethanol and then dried in a critical point dryer before sputter coating in gold using standard electron microscopic procedures. Observation of the coated specimens was in a Phillips XL-20 scanning electron microscope. Representative images were photographed and assembled into figures as described above. 


\section{Results}

\section{Histology and ultrastructure of the annulus fibrosus}

At E15, disc primordia consisted of dense condensations of peri-notochordal mesenchyme situated between adjacent cartilaginous vertebral bodies (Fig. 1A). The notochord was visible as a compact rod of cells separated from the surrounding mesenchyme by a thin sheath of fibrillar ECM (Fig. 1A, B). Within the intervertebral condensations, mesenchymal cells were intimately associated with one another by multiple cell processes, creating discrete compartments of intercellular space. By E16, the notochord had bulged intervertebrally; giving rise to the incipient nucleus pulposus, and the surrounding disc tissue had differentiated into cartilaginous inner and fibroblastic outer annuli (Fig. 1C, D). Parasagittal section planes through the outer annulus revealed a striking lattice-like arrangement of cells, evidencing the alternating cellular orientations within successive fibroblastic laminae (Fig. 1D). This cross-ply arrangement of alternately oriented cell sheets could also be seen at the ultrastructural level (Fig. 1E). Fibroblasts within each lamina were spindle-shaped, highly elongate and contained prominent stress-fibre bundles beneath their plasma-membranes (Fig. 1E, inset) as described previously (Hayes et al., 1999). At this stage there was little fibrillar ECM between adjacent laminae; however, by E19, oriented bundles of collagen had formed rudimentary lamellae between adjacent cell sheets (Figs. 1F and 4F). Fibroblasts could be seen contributing to the overall growth of their associated lamellae by means of oriented fibrils deposited from recesses within their plasma membrane (Fig. 1F). The orientation of fibre bundles within these lamellae reflected the initial cellular orientation of laminae first observed at E16 (Figs. 1G and 5F). During post-natal growth, there was progressive accumulation of fibrillar matrix within the annulus, so that by 4 months the lamellae had thickened considerably (Figs. $1 \mathrm{H}$ and $6 \mathrm{~F}$ ). With advancing age, the lamellar organisation of the annulus remained apparent; however, the fine fibrillar appearance of its ECM became less evident (Fig. 1I).

\section{Immunohistochemistry}

\section{Antibody labelling controls}

All immunohistochemical labelling controls at each developmental stage investigated were negative, showing no non-specific antibody labelling (4-month adult discs depicted; Fig. 2A-D).

\section{Antibody labelling patterns}

The antibody labelling patterns observed at each developmental stage are summarised in Table 2. The following representative stages are depicted in the accompanying figures to convey these trends: E15, predisc differentiation (Fig. 3); E19, post-disc differentiation (Figs. 4 and 5); 4 month, adult (Figs. 6 and 7); and 24 month, aged (Fig. 8).

\section{Heparan sulphate expression}

At E15, prior to disc differentiation, immunohistochemical labelling with antibodies 10E4 and 3G10 showed that both native HS and the delta-4,5 uronate HS stub neoepitope, respectively, were expressed on cell surfaces throughout the disc primordium (Fig. 3A,B); whereas, only the latter was prominent within notochordal tissue (Fig. 3B). At E16, after disc differentiation had occurred and for the remainder of foetal development HS and the HS stub neoepitope shared overlapping expression patterns on cell surfaces within the constituent spinal tissues (E19 disc depicted; Fig. 4A, B). Both HS isoforms were expressed by chondrocytes of the cartilaginous vertebral bodies and inner annulus, with weaker expression associated with the fibroblastic laminae of the outer annulus (Figs. 4A, B and 5A, B). Of the two HS epitopes, the HS stub neoepitope was most strongly expressed within notochordal tissue of the developing nucleus pulposus (Fig. 4B). At 4 months,

Fig. 1. (Next page) Development of the annulus fibrosus of the intervertebral disc. A. Semi-thin resin section (mid-sagittal plane) of an E15 lumbar intervertebral disc anlagen prior to differentiation. The disc consists of a dense condensation of intervertebral mesenchyme (iv) that surrounds the notochord $(n)$. Dashed lines demarcate tissue boundary between developing disc and vertebral body $(v b)$. Toluidine blue staining. B. Electron micrograph showing detail of intervertebral condensation ( $i v$ ) depicted in A. Cells are intimately associated with one another (arrow heads), creating compartments of extracellular space. The intervertebral mesenchyme is separated from the notochord $(n)$ by the notochordal sheath $(n s)$. C. Paraffin wax section (mid-sagittal plane) through an E16 lumbar intervertebral disc. The notochord has expanded intervertebrally forming the nucleus pulposus $(n p)$ and the intervertebral mesenchyme has differentiated into annulus fibrosus. The inner part of the annulus $(i a)$ is cartilaginous, whereas the outer annulus $(o a)$ is fibroblastic. $v b$, vertebral bodies. Alcian blue and H \& E. D. Paraffin wax section (parasagittal plane) through an E16 disc showing detail of the oriented cell sheets of the outer annulus $(o a) . v b$, vertebral bodies. Alcian blue and H \& E. E. Electron micrograph of the outer annulus at E16. Cells are tightly arranged in alternately oriented laminae (black asterisks denote laminae cut in longitudinal plane; white asterisks indicate transversely sectioned laminae). Boxed area (inset) shows detail of stress fibres ( $s f)$ within a longitudinally sectioned cell sheet; dashed line demarcates cell membrane. F. Electron micrograph of the outer annulus at E19 showing collagen deposition from cell membrane recesses (arrow). Black asterisk denotes a longitudinally sectioned collagenous lamella. G. Semi-thin resin section of the outer annulus at the neonate stage. Cell laminae are separated by rudimentary collagenous lamellae (black asterisks denote lamellae cut in longitudinal plane; white asterisks indicate obliquely sectioned lamellae). Toluidine blue staining. H. Scanning electron micrograph showing fibrillar architecture of annular lamellae (superior surface) of a 4 month intervertebral disc. I. Scanning electron micrograph showing annular lamellae of a 24 month disc (superior surface). The fine fibrillar architecture of lamellae is less obvious at this stage. All scale bars shown in $\mu \mathrm{m}$. 

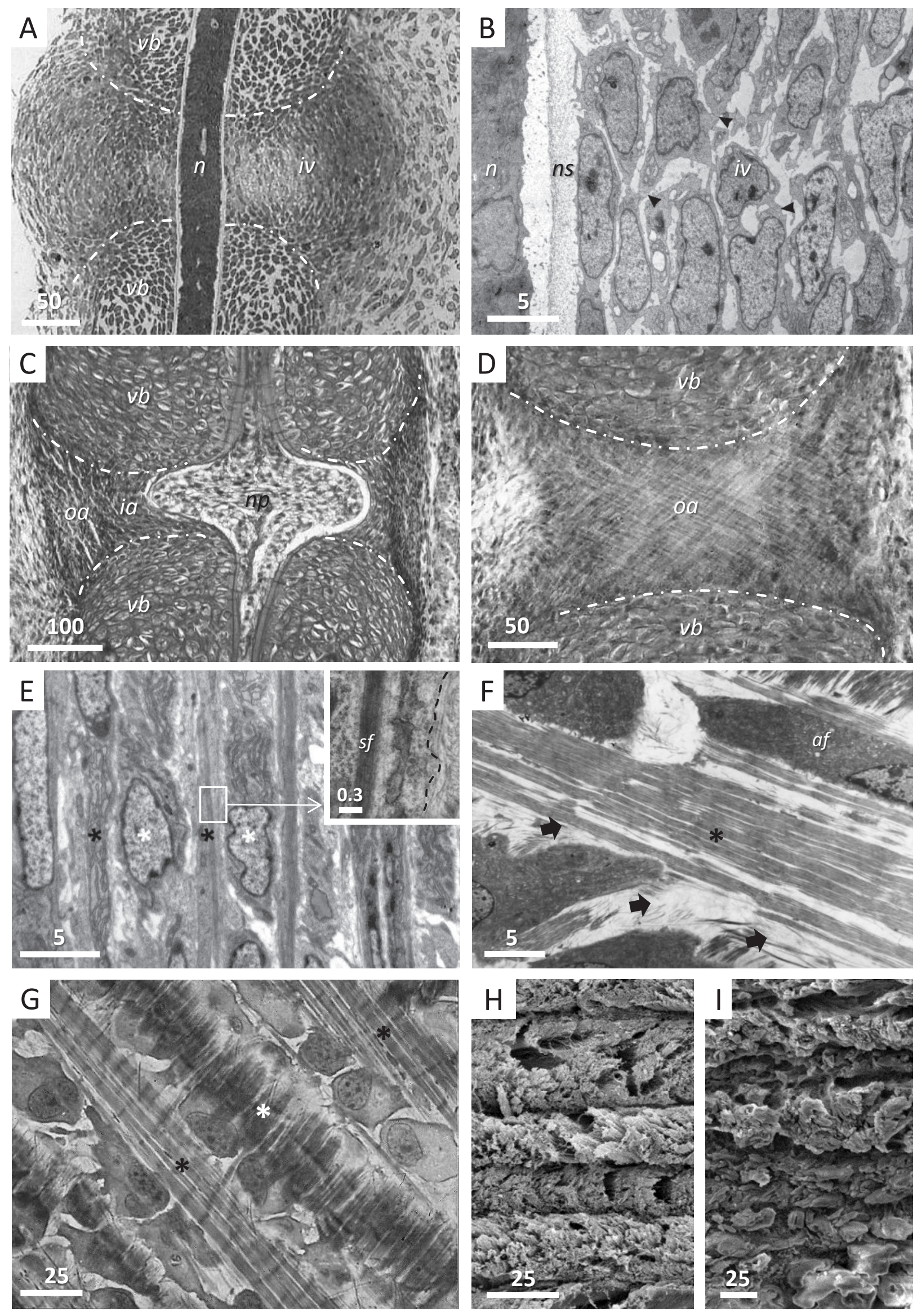

Fig. 1. 
Fig. 2. Immunohistochemical labelling controls. Tissue sections of 4 month lumbar intervertebral disc (mid-sagittal plane) show no non-specific antibody labelling. N.B. Sections have been lightly counterstained with haematoxylin for tissue context. A. Primary antibody replaced with nonimmune (i.e. naïve) immunoglobulin. B. Primary antibody replaced with antibody diluent (PBS). C. Heparatinase pre-treatment of tissue before incubation with $\mathrm{mAb} 10 \mathrm{E} 4$ (mAb 10E4 recognises native, i.e. intact, heparan sulphate). D. Omitting heparatinase treatment prior to incubation with mAb 3G10 (mAb 3G10 recognises a heparitinasegenerated heparan sulphate neo-epitope). Dashed lines demarcate tissue boundaries between disc and vertebral body. cep, cartilage endplate; $i a$, inner annulus; $n p$, nucleus pulposus; $o a$, outer annulus; $v b$, vertebral body. All scale bars shown in $\mu \mathrm{m}$.
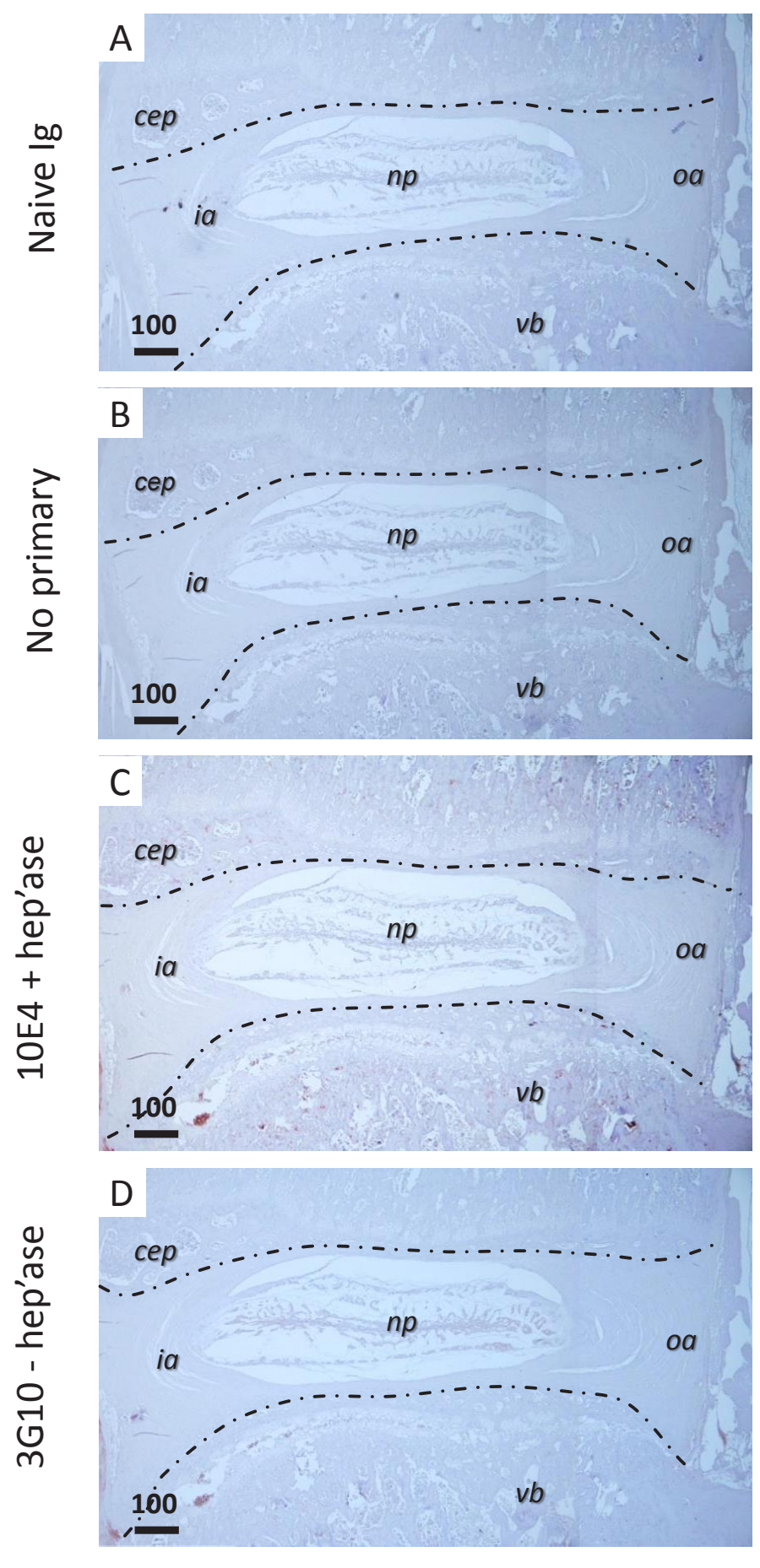

both HS isoforms were strongly associated with the surface of annulus cells (Fig. 6A, B), with weaker expression in cartilage endplate (Fig. 7A, B). The growth plate also labelled strongly for both HS epitopes (Fig. 7A, B), consistent with the known abundance of HS on growth plate perlecan (Smith et al., 2007). By 24 months, both HS isoforms remained prominent on cell surfaces throughout the constituent disc tissues (Fig. 8A, B). At this stage, the $3 \mathrm{G} 10 \mathrm{HS}$ stub neoepitope was strongly expressed by chondrocyte clusters within the nucleus pulposus (Fig. 8B). Whilst the expression of both HS isoforms remained prominent within growth plate, no labelling was detected within the cartilage end-plate at this stage (Fig. 8A, B).

\section{Glypican-6 expression}

Glypican-6 was weakly expressed on cell surfaces of the disc primordium at E15 with strongest expression associated with the notochordal sheath (Fig. 3C). After disc differentiation had occurred at E16, and during subsequent foetal stages, glypican-6 was expressed on cell surfaces throughout the constituent disc tissues and within the vertebral bodies (E19 disc depicted; Figs. 4C and $5 \mathrm{C}$ ); its labelling pattern closely matching those of the HS isoforms (compare with Figs. 4A, B and 5A, B). At 4 months, glypican- 6 label decorated cell surfaces throughout the annulus (Fig. 6C) and was prominent within the growth plate (Fig. 7C). At 24 months, glypican-6 label 
Table 2. Summary of immunohistochemical labelling patterns within vertebral tissues.

\begin{tabular}{|c|c|c|c|c|c|c|c|c|}
\hline Antibody & Tissue & \multicolumn{2}{|c|}{ E15* } & E17 & E19 & Neo & 4 month & 24 month \\
\hline \multirow{4}{*}{ 10E4 (native HS) } & $N / N P$ & \multicolumn{2}{|l|}{-} & + & + & + & ++ & ++ \\
\hline & $I A$ & \multirow{2}{*}{++} & \multirow{2}{*}{ (1) } & ++ & ++ & ++ & +++ & ++ \\
\hline & $O A$ & & & ++ & ++ & ++ & +++ & ++ \\
\hline & $V B$ & + & & ++ & ++ & ++ & +++ & ++ \\
\hline \multirow{4}{*}{ 3G10 (HS stub) } & $N / N P$ & \multicolumn{2}{|l|}{+} & ++ & +++ & +++ & +++ & ++ \\
\hline & $I A$ & \multirow{2}{*}{++} & \multirow{2}{*}{ (1) } & + & +++ & +++ & +++ & ++ \\
\hline & $O A$ & & & + & + & + & +++ & ++ \\
\hline & $V B$ & \multicolumn{2}{|l|}{-} & ++ & +++ & +++ & +++ & ++ \\
\hline \multirow{4}{*}{ T20 (GPC6) } & $N / N P$ & ++ & (2) & +++ & +++ & +++ & +++ & ++ \\
\hline & $I A$ & \multirow{2}{*}{+} & \multirow{3}{*}{ (1) } & +++ & +++ & +++ & +++ & ++ \\
\hline & $O A$ & & & + & + & + & +++ & ++ \\
\hline & $V B$ & + & & +++ & +++ & +++ & +++ & ++ \\
\hline \multirow{4}{*}{ SDC4 } & $N / N P$ & + & (2) & + & + & ++ & +++ & +++ \\
\hline & $I A$ & \multirow{2}{*}{+} & \multirow{2}{*}{ (1) } & + & ++ & ++ & +++ & ++ \\
\hline & $O A$ & & & +++ & +++ & +++ & +++ & ++ \\
\hline & $V B$ & ++ & & + & + & + & +++ & ++ \\
\hline \multirow{4}{*}{ FN (fibronectin) } & $N / N P$ & \multicolumn{2}{|l|}{+} & + & +++ & +++ & +++ & +++ \\
\hline & $I A$ & \multirow{2}{*}{++} & \multirow{3}{*}{ (1) } & + & +++ & +++ & +++ & ++ \\
\hline & $O A$ & & & +++ & +++ & +++ & +++ & ++ \\
\hline & $V B$ & + & & + & ++ & ++ & +++ & ++ \\
\hline
\end{tabular}

$N / N P$, notochord/nucleus pulposus; $I A$, inner annulus; $O A$, outer annulus; $V B$, vertebral body. -, absence of labelling; +, weak labelling; ++, moderate labelling; +++ , strong labelling. (1) staining within disc condensation; (2) staining within notochordal sheath. *, pre-disc differentiation.

was, in addition, associated with chondrocyte clusters at the margins of the nucleus pulposus (Fig. 8C).

\section{Syndecan-4 expression}

Syndecan-4 was weakly expressed on cell surfaces of the disc primordia at E15, with diffuse labelling throughout the vertebral bodies. Syndecan-4 label, like that of glypican-6, was also strongly associated with the notochordal sheath at this stage (Fig. 3D). After disc differentiation at E16, and for the remainder of foetal development, syndecan-4 became highly organised on oriented cell surfaces of the outer annulus (E19 disc depicted; Figs. 4D and 5D). Syndecan-4 remained strongly associated with cell surfaces of the annulus at 4 months, with weaker matrix labelling of the inner, but not outer annulus (Fig. 6D). Syndecan-4 was also strongly detectable within growth plate, but not cartilage end plate at this stage (Fig. 7D). At 24 months, syndecan-4 expression had diminished somewhat within the annulus, but its expression remained strong within the nucleus pulposus and growth plate. As with HS and glypican-6, it too was strongly associated with chondrocyte clusters within the nucleus pulposus (Fig. 8D).

\section{Fibronectin expression}

Fibronectin was ubiquitously expressed on cell surfaces within the disc primordia and vertebral bodies at E15 (Fig. $3 \mathrm{~A})$, becoming prominent within the outer annulus after the initial cellular orientation phase, as reported previously (Hayes et al., 1999, 2001). Fibronectin was highly organised on oriented cell surfaces of the annular laminae throughout the remainder of foetal development (E19 disc depicted; Figs. 4E and 5E), its expression pattern closely matching that of syndecan-4 (compare Figs. 5D and 5E). At 4 months, fibronectin was highly expressed within the pericellular microenvironment of the outer annulus and, more broadly, throughout the ECM of the inner annulus (Fig. 6E). In this respect, its expression pattern overlapped with that of syndecan-4; however, fibronectin labelling was less conspicuous within the growth plate (Fig. 7E). At 24 months, fibronectin remained broadly expressed within the disc; however, it was noticeably absent from the chondrocyte clusters of the nucleus pulposus (Fig. 8E).

\section{Collagen organisation}

At E15, there was no collagen detectable within the intervertebral mesenchyme at light or electron microscopic levels; however the notochord was surrounded by a fibrillar, birefringent sheath (Figs. 1B and 3F), as reported previously (Hayes et al., 2011b). Following the cellular orientation phase in the outer annulus at E16, there was a progressive accumulation of fibrillar ECM between cell sheets and rudimentary collagenous lamellae were clearly visible at both light and electron microscopic levels at later foetal stages (Figs. 1F, 1G, 4F and 5F). By 4 months, the annular lamellae had undergone considerable enlargement and were highly birefringent under polarising optics (Figs. $1 \mathrm{H}, 6 \mathrm{~F}$ and $7 \mathrm{~F}$ ); the alternating orientation of collagen within adjacent lamellae reflecting the initial cellular orientation of the foetal annulus and their underlying stress fibres. At 24 months, the annular lamellae remained highly birefringent; however, their fine fibrillar organisation was less obvious through progressive accumulation of ECM (Figs. 1I and 8F). 

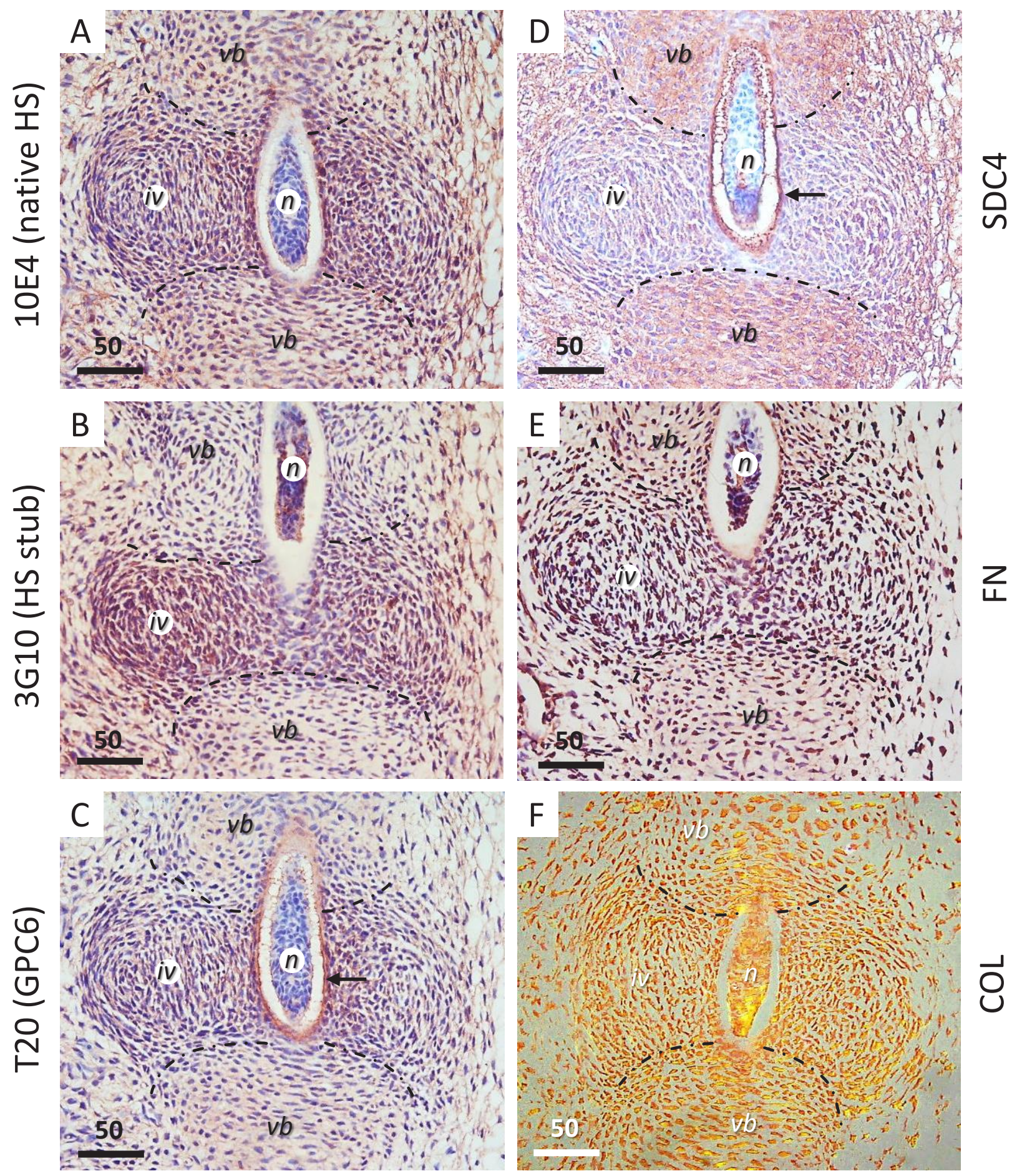

Fig. 3. Immunohistochemistry of foetal rat disc primordia (mid-sagittal plane) at E15. At this stage the disc has not yet differentiated and consists of dense intervertebral mesenchyme surrounding the notochord. $\mathbf{A}$ and $\mathbf{B}$. Immunohistochemical labelling with mAbs 10E4 and 3G10 demonstrate widespread cellular expression of native HS and HS stub neoepitope, respectively. C. Labelling with antibody T20 shows similar widespread glypican-6 (GPC6) expression throughout the disc condensation, particularly of notochordal sheath (arrow). D. Syndecan-4 (SDC4) is identifiable throughout the disc condensations, but with stronger expression in the vertebral bodies and notochordal sheath (arrow). E. Cellular fibronectin (FN) occurs throughout the disc condensations and within the vertebral bodies. F. Polarising microscopy shows that the disc primordia are highly cellular at this stage, with only weak collagen birefringence (COL) associated with the notochord and its surrounding sheath. Picrosirius red staining. Dashed lines demarcate tissue boundaries between disc and vertebral body. $i v$, intervertebral mesenchyme; $n$, notochord; $v b$, vertebral body. All scale bars shown in $\mu \mathrm{m}$. 

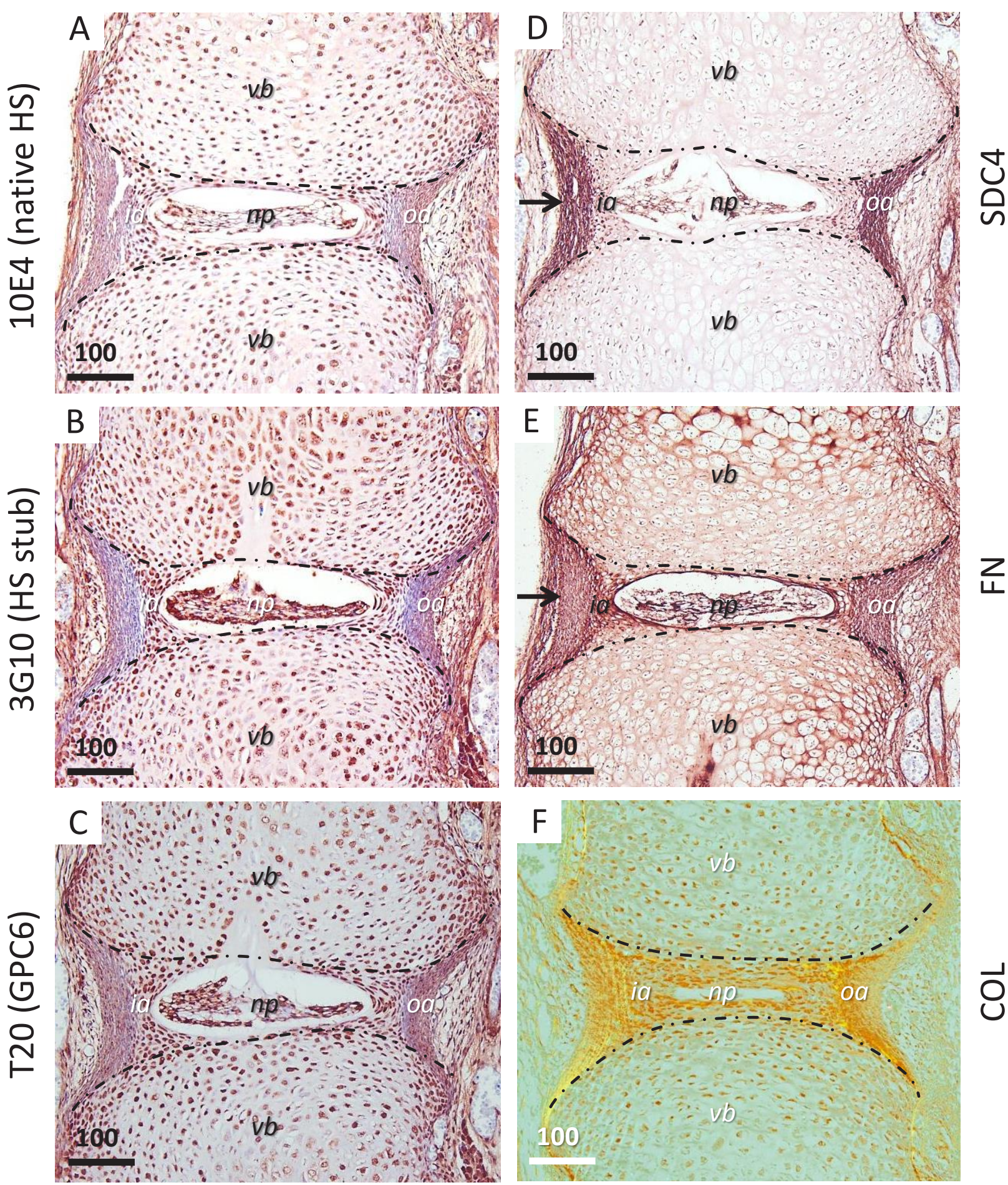

Fig. 4. Immunohistochemistry of the foetal rat intervertebral disc (mid sagittal plane) at E19. At this stage the notochord has expanded to form the nucleus pulposus and the intervertebral mesenchyme has differentiated into cartilaginous inner and fibroblastic outer annulus. A and B. mAbs 10E4 and 3G10 show strong cell-associated expression of native HS and HS stub neoepitope, respectively, within the vertebral cartilages, with weaker expression in the fibroblastic outer annulus. The $3 \mathrm{G} 10 \mathrm{HS}$ stub is also highly prominent within the nucleus pulposus. C. Labelling with antibody T20 shows that glypican-6 (GPC6) has an overlapping expression pattern with the HS epitopes. D. Syndecan-4 (SDC4) is highly expressed within the outer annulus of the disc (arrow). E. Fibronectin (FN) is widely expressed in spinal tissues but is prominent within the outer annulus and nucleus pulposus. F. Polarising microscopy shows strong collagen (COL) birefringence associated with the incipient lamellae of the annulus fibrosus. Picrosirius red staining. $i a$, inner annulus; $o a$, outer annulus; $n p$, nucleus pulposus; $v b$, vertebral body. Dashed lines demarcate tissue boundaries between disc and vertebral body. All scale bars shown in $\mu \mathrm{m}$. 

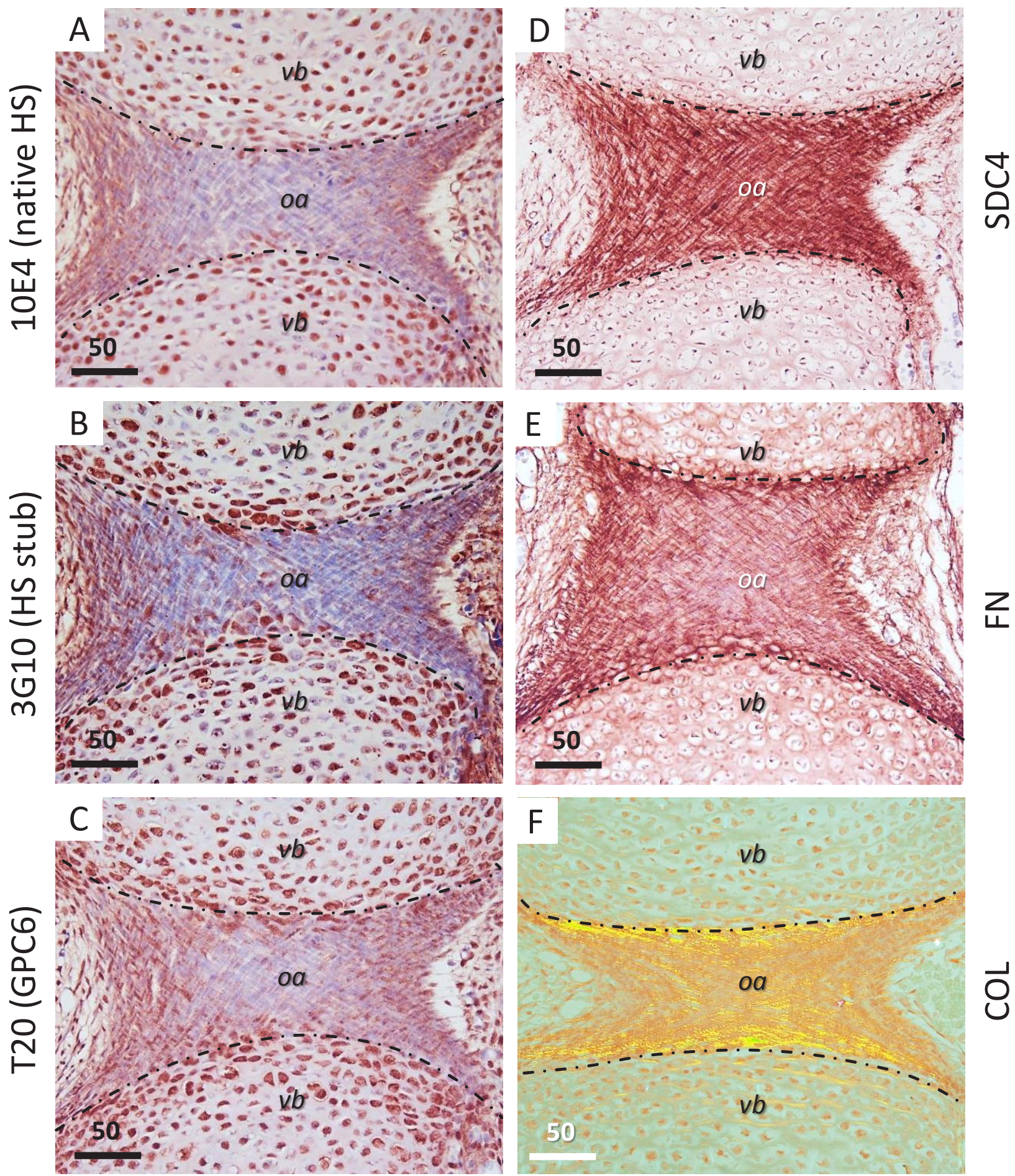

Fig. 5. Immunohistochemistry of the foetal rat intervertebral disc (parasagittal section plane) at E19 showing detail of the outer annulus fibrous. The alternating orientation of cells in successive laminae of the outer annulus manifests as a cellular lattice in this glancing section plane. A and B. Immunohistochemical labelling with $\mathrm{mAbs}$ 10E4 and 3G10 show strong cell-associated expression of native HS and HS neoepitope within the vertebral bodies, inner annulus and nucleus pulposus. Both HS epitopes are expressed more weakly within with the outer annulus. C. Labelling with antibody T20 shows that glypican-6 (GPC6) has a similar, overlapping expression pattern with the HS epitopes. D and E. Syndecan-4 (SDC4) and fibronectin (FN) are both highly expressed on oriented cell surfaces of the outer annulus. F. Polarising micrograph showing collagen birefringence (COL) associated with the incipient lamellae of the outer annulus. Picrosirius red staining. oa, outer annulus; $v b$, vertebral body. Dashed lines demarcate tissue boundaries between disc and vertebral body. All scale bars shown in $\mu \mathrm{m}$. 

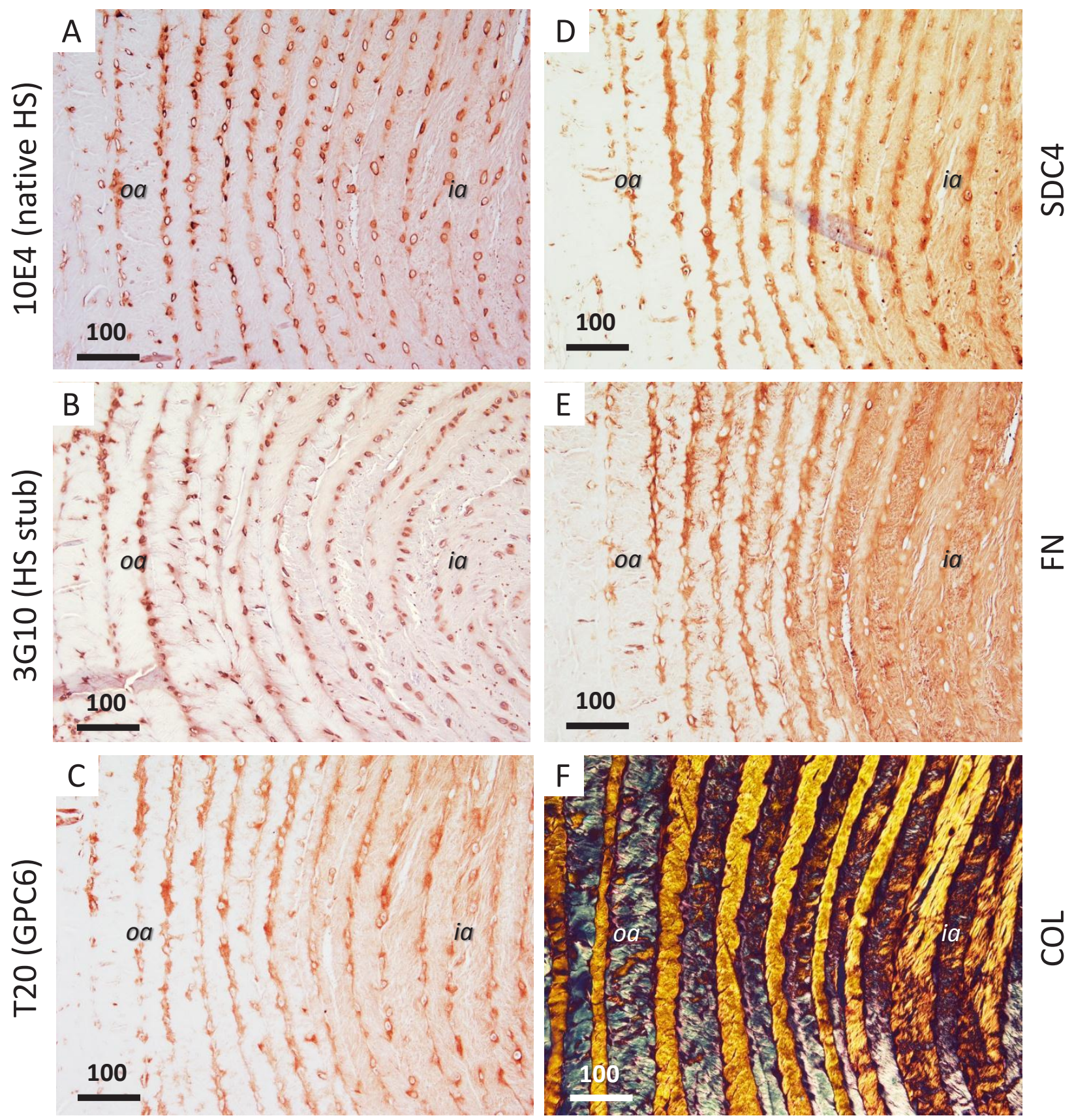

Fig. 6. Immunohistochemistry of the 4 month rat annulus. Images are of mid-sagittal sections through the anterior annulus of the L1/2 disc. A and B. Immunohistochemical labelling with mAbs 10E4 and 3 G10 identifies both native HS and HS neoepitope on cell surfaces between contiguous lamellae. C and D. Glypican-6 (GPC6) and syndecan-4 (SDC4) are also strongly associated with the pericellular microenvironment of annulus cells. Syndecan-4 expression is also detectable within the ECM of the inner annulus at this stage. E. Fibronectin (FN) has an overlapping expression pattern with both glypican-6 and syndecan-4 within the pericellular microenvironment. It is also detectable within the wider ECM of inner annulus at this stage. F. Polarising micrograph showing the strongly lamellar organisation of birefringent collagen (COL) within the annulus. Picrosirius red staining. ia, inner annulus; oa, outer annulus. All scale bars shown in $\mu \mathrm{m}$.

\section{Discussion}

This is the first ontogenical study describing the expression of syndecan-4, glypican-6 and HS in the rat IVD. We have previously shown this species to be a good animal model for early human IVD development (Hayes et al., 1999, 2001, 2011a, 2011b); however, there are notable interspecies differences (Alini et al., 2008); for example rats, unlike humans, retain notochordal cells within their nucleus

pulposus throughout life; although both show similar agerelated discal pathologies (see below). This study adds to our previous findings on disc development, indicating that both HSPGs play diverse functional roles within the constituent disc tissues during development, growth and aging. Furthermore, it highlights a potentially-significant role for syndecan- 4 in the establishment of the annulus fibrosus of the foetal disc. 

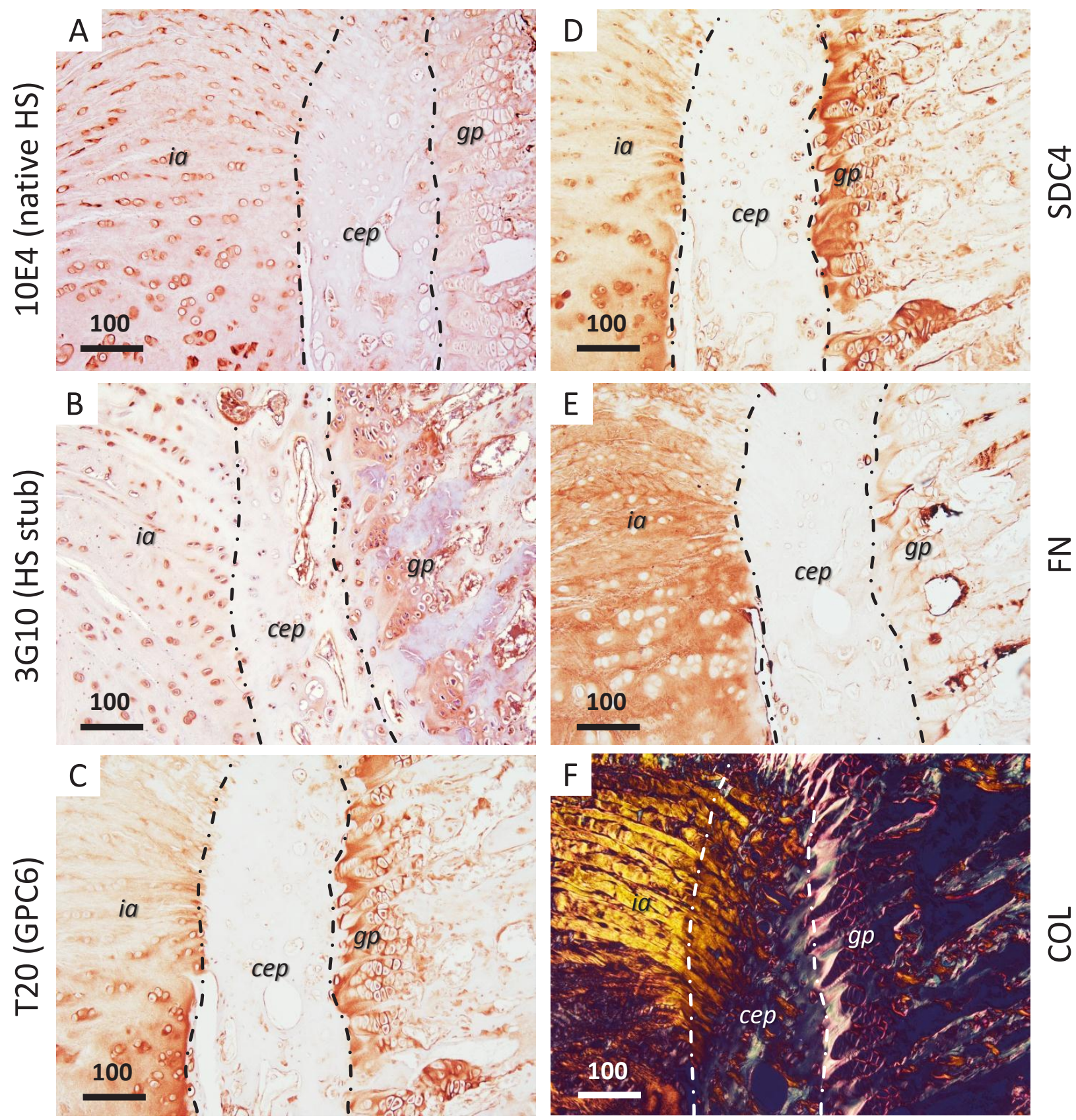

Fig. 7. Immunohistochemistry of the 4 month rat intervertebral disc. Images are of mid-sagittal sections of the L1-2 disc showing the attachment of anterior annulus to superior end-plate. A and B. mAbs 10E4 and 3G10 give prominent cell surface labelling of native HS and HS neoepitope within the inner annulus and growth plate, with weaker expression in the cartilage end plate. C and D. Glypican-6 (GPC6) and syndecan-4 (SDC4) are detectable both around cells and within the surrounding matrix of inner annulus and growth plate, but are only weakly expressed in the cartilage endplate. E. Fibronectin (FN) label is prominent throughout the ECM of inner annulus with weaker expression in growth plate. F. Polarising micrograph showing collagen birefringence (COL) at the interface between inner annulus and cartilage endplate. Picrosirius red staining. Dashed lines demarcate tissue boundaries between inner annulus (ia), cartilage endplate (cep) and vertebral growth plate $(g p)$. All scale bars shown in $\mu \mathrm{m}$.

Of the syndecan family of HSPGs, syndecan-4 is probably the best understood in terms of its structure, molecular interactivity and biological function. The molecule consists of a short cytoplasmic domain comprising two highly conserved regions ( $\mathrm{C} 1$ and $\mathrm{C} 2)$ flanking a variable (V) region; a transmembrane domain; and an ectodomain with three potential GAG attachment sites for HS and CS chains (Bernfield and Sanderson, 1990; Shworak et al., 1994). The attached GAGs interact with a variety of structural matrix components, including collagen types I, III and V, fibronectin, tenascin and thrombospondin (Bernfield and Sanderson, 1990; Carey, 1997; Choi et al., 2011; Tumova et al., 2000) as well as matrix growth factors (e.g., bFGF) and cytokines (Deepa et al., 2004; Lopes et al., 2006). The intracellular domains of syndecan-4, meanwhile, allow interaction with numerous cytosolic binding partners involved in mechanotransduction and signalling. The interaction of syndecans cytoplasmic 

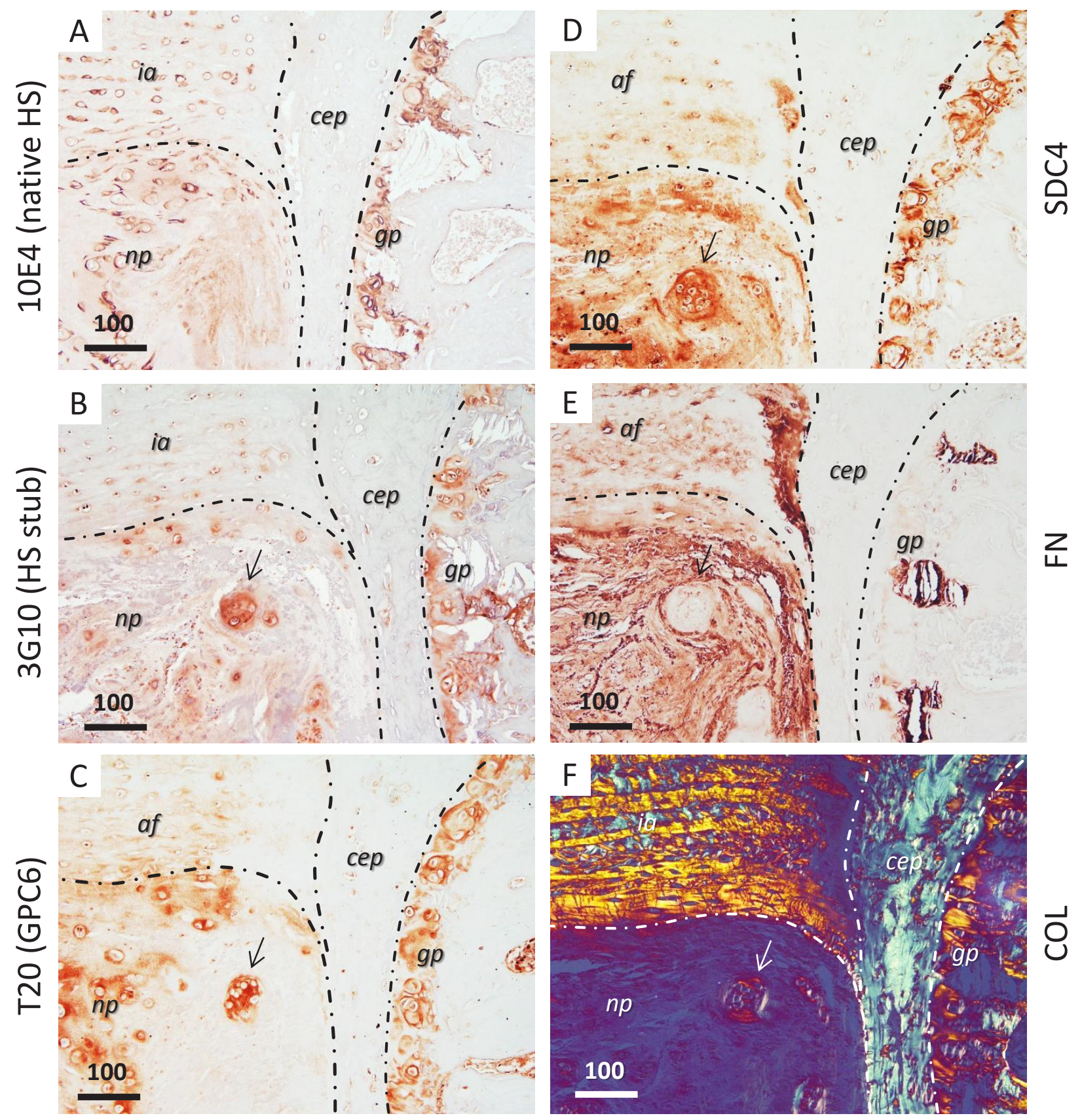

Fig. 8. Immunohistochemistry of the 24 month rat intervertebral disc. Images are of mid-sagittal sections of the L1-2 disc showing attachment of anterior annulus to superior end-plate. A and B. mAbs 10E4 and 3G10 identify native HS and HS stub neoepitope, respectively, within the inner annulus, nucleus pulposus and growth plate. $\mathbf{C}$ and $\mathbf{D}$. Glypican-6 (GPC6) and syndecan-4 (SDC4) have broadly overlapping expression patterns with the HS isoforms. E. Fibronectin (FN) is broadly expressed, but strongly associated with cells of notochordal origin. Arrows denote a chondrocyte cluster within the nucleus. F. Polarising microscopy showing collagen birefringence (COL) within the constituent disc tissues. Dashed lines demarcate tissue boundaries between inner annulus ( $\mathrm{ia}$ ), nucleus pulposus ( $\mathrm{np}$ ), cartilage endplate (cep) and vertebral growth plate $(g p)$. All scale bars shown in $\mu \mathrm{m}$.

domain with the cytoskeletal protein $\alpha$-actinin is important for cell-ECM adhesion and in regulating the architecture of the actin cytoskeleton (Okina et al., 2012). The cytoplasmic domain can also regulate the activity of many intracellular signalling molecules (Elfenbein and Simons, 2013). These include focal adhesion kinase - a key mechanosensory molecule that affects cell adhesion, shape and spreading (Wilcox-Adelman et al., 2002); and protein kinase C and the downstream Rho GTPases (e.g., RhoG, Rac1 and RhoA) that are involved in focal adhesion assembly, actin remodelling and cell motility (Brooks et al., 2012). This broad molecular interactivity allows syndecan-4, in concert with the integrins (Bass et al., 2007; Saoncella et al., 1999), to regulate a wide range of cellular behaviours (e.g., cell adhesion, spreading, motility etc.) of fundamental importance in tissue morphogenesis and repair (Longley et al., 1999). The expression and organisation of this PG on oriented cell surfaces of the foetal outer annulus, post 


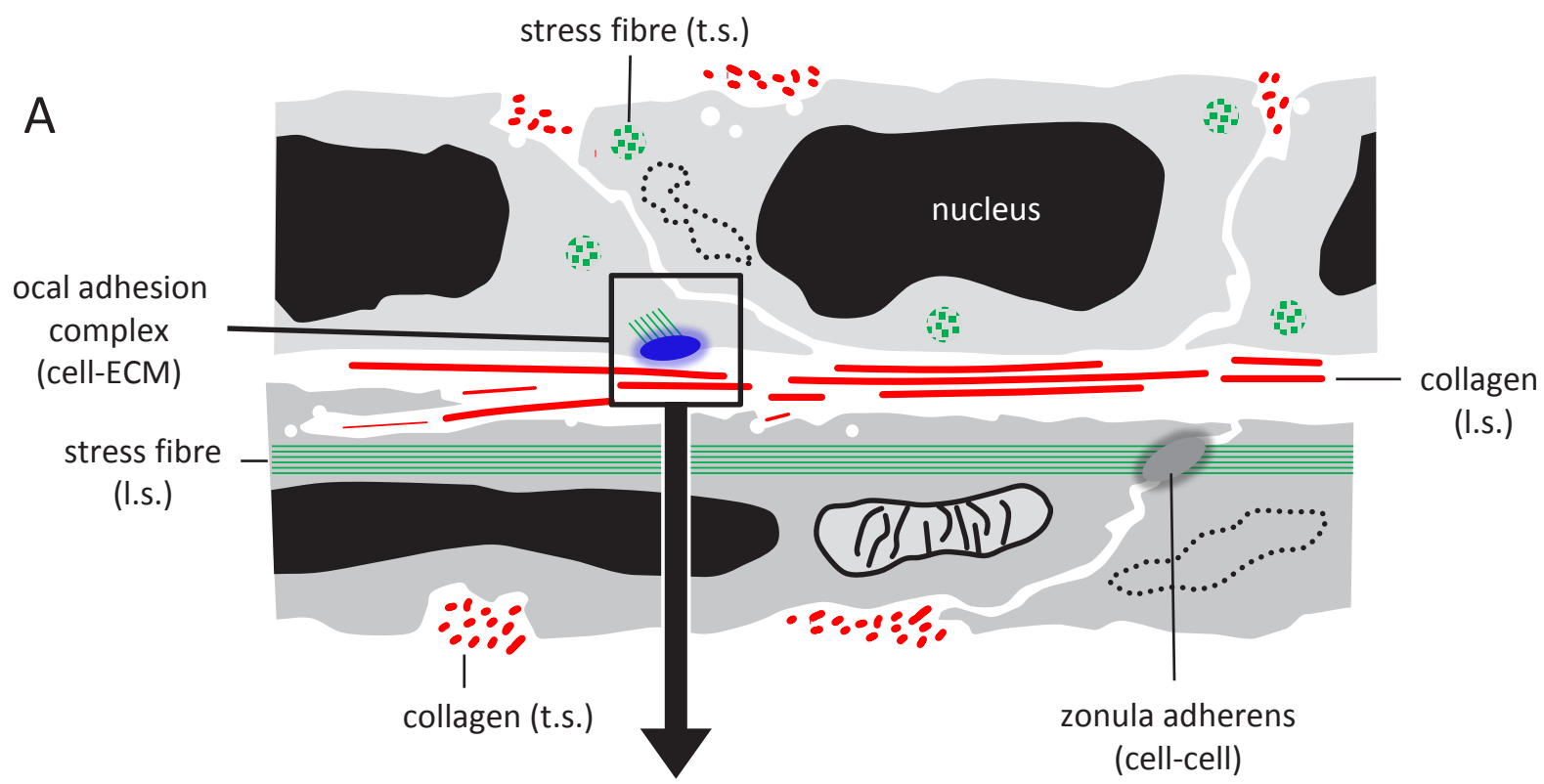

B

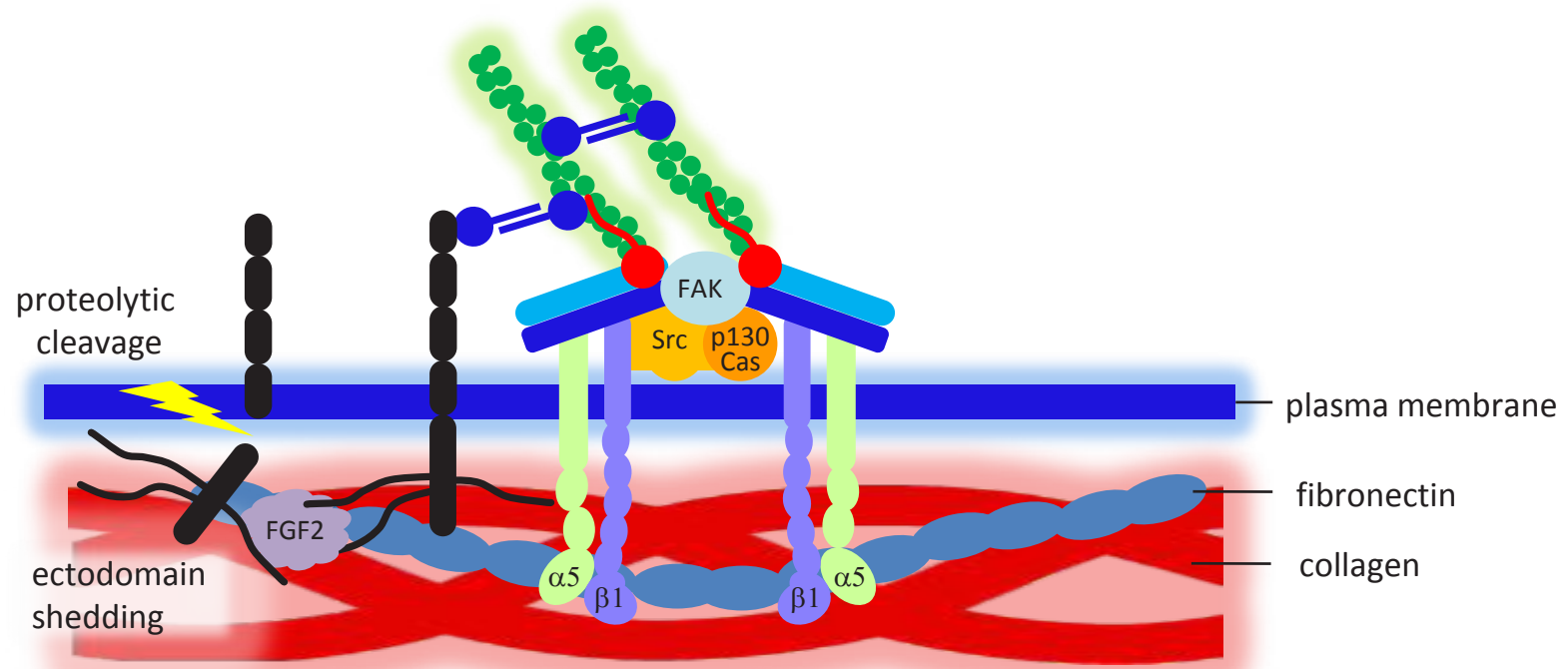

Key to schematic:

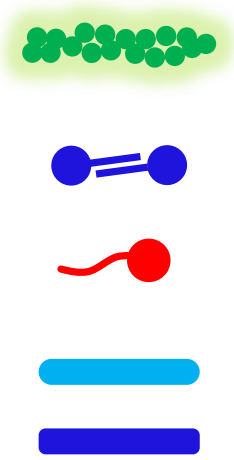

actinomyosin stress fibre

$\alpha$ actinin

vinculin

paxillin

talin

focal adhesion kinase

tyrosine kinase

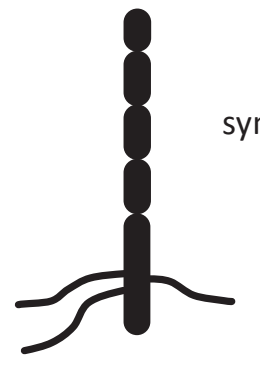

HS/CS GAG signalling molecule

integrin fibroblast growth factor

Fig. 9. 
Fig. 9. (Previous page) Schematic summarising potential roles of syndecan-4 in annulus formation. A. Diagram illustrating the cross-ply structure of the foetal annulus. Two adjacent laminae are depicted: the long axis of cells in the uppermost lamina are oriented at $90^{\circ}$ with respect to those in the subjacent lamina. Underlying the cellular template of the annulus is an intracellular network of oriented actomyosin stress fibres. Cells within individual laminae are mechanically coupled to their neighbours by means of actin-associated adherens junctions and to their surrounding ECM by focal adhesion complexes. Stress fibres direct the initial elongation of annulus cells and control the deposition of oriented extracellular matrix on cell surfaces and between cell sheets by focal adhesion complexes. B. Diagram illustrating molecular interactivity of syndecan-4 within a focal adhesion plaque. Actomyosin stress fibres are anchored within the focal contact by means of an assortment of cytoskeletal adhesion molecules (refer to key), which include vinculin. These attach to integrins such as $\alpha 5 \beta 1$ that function as transmembrane receptors for cell surface fibronectin and extracellular collagen (Hayes et al., 1999). Syndecan-4 cooperates with the $\alpha 5 \beta 1$ integrin to promote the formation of stress fibres and focal adhesions during annulus formation. It binds directly to fibronectin as well as to other matrix ligands including growth factors such as bFGF. The ectodomain of syndecan-4 can also be shed by proteolytic cleavage of its core protein, yielding a soluble proteoglycan effector that may regulate growth factor activity within the extracellular milieu. t.s. transversely sectioned; l.s. longitudinally sectioned.

disc-differentiation, suggests that it has central involvement in mediating the profound changes in cell shape and tissue reorganisation that accompany the initial cell-ECM orientation phase at this time (refer to Fig. 9).

Syndecan-4 is a key component of the mechanosensory/ mechanotransductive apparatus of fibroblasts. Biomechanical stress regulates both its expression and distribution on cell surfaces, thereby influencing cell morphology, movement and orientation (Bellin et al., 2009; $\mathrm{Li}$ and Chaikof, 2002). This property may be important in the initial cellular response of annulus cells to notochordal expansion. During foetal development, annulus cells are intimately connected to one another by adherens-type junctions and surround an enlarging structure, i.e., the expanding notochord, so they would experience both compressive and tensile forces (Hayes et al., 1999). These forces may drive syndecan-4 expression and organisation on cell surfaces within the annulus and, in turn, trigger the assembly of focal adhesion complexes and actomyosin stress fibres (Okina et al., 2012; Saoncella et al., 1999). These events could (1) impact cellular morphology and orientation, with stress fibre assembly driving the elongation and alignment of cells relative to lines of mechanical stress experienced within the tissue, and (2) result in the activation of mechano-transduction pathways that promote ECM synthesis and secretion (Asparuhova et al., 2009; Chiquet et al., 2009; Chiquet et al., 2003). The mechanically-tensioned network of oriented stress fibres, linked by adherens-type junctions, might not only provide a mechanism by which annulus cells could sense and respond to their physical surroundings in a coordinated manner, but could serve also as an intracellular template/ conduit for organised deposition of ECM on oriented cell surfaces, e.g., via myosin-based vesicular transport (DePina and Langford, 1999; Pellegrin and Mellor, 2007; Pompe et al., 2005; Wang et al., 2003).

The close correlation in expression patterns of syndecan-4 and fibronectin on cell surfaces of the annulus, with the stage-specific collagenous architectures identifiable between laminae, underlines a potentially important role for these molecules as organisers/mediators of collagen fibrillogenesis within the developing annulus (refer to Fig. 9). It seems likely that syndecan-4 acts synergistically with the integrins, particularly $\alpha 5 \beta 1$, to direct the self-assembly of fibronectin and collagen on oriented cell surfaces of the foetal annulus (Bass et al., 2007; Couchman and Woods, 1999; Dzamba et al., 1993; Mao and Schwarzbauer, 2005; Morgan et al., 2007; Saoncella et al., 1999; Wu et al., 1993). Fibronectin binds collagen and mediates the co-assembly of oriented fibrils at plasma membrane recesses and/or by fibropositors (Canty et al., 2004; Kadler et al., 2008; McDonald et al., 1982; Sevilla et al., 2013). The stepwise organisation of collagen, from oriented fibrils into bundles and then bundles into highly ordered lamellae, might ensue via a series of hierarchical extracellular compartments, as occurs in cornea and tendon, under the control of matrix organisers, such as the FACIT collagens and SLRPs, as well as regulatory growth factors, e.g., TGF- $\beta$, bFGF etc. (Banos et al., 2008; Birk and Trelstad, 1984, 1986; Hayes et al., 2011b; Jin et al., 2011; Kadler et al., 2008; Young et al., 2014; Zhang et al., 2005).

Cellular fibronectin and HS linked to cell surface PGs can also direct the formation of oriented fibrillinmicrofibrils and elastic fibres, and promote the association of fibrillin with latent-TGF- $\beta$ binding protein (LTBP-1), a molecule involved in the targeting of TGF- $\beta 1$ to sites at which it is stored and/or activated (Baldwin et al., 2014; Cain et al., 2008; Kinsey et al., 2008; Sabatier et al., 2009; Sabatier et al., 2014; Saharinen et al., 1999; Zilberberg et al., 2012). The co-occurrence of these molecules within the developing annulus, as shown previously (Hayes et al., 2014; Hayes et al., 2011c; Hayes et al., 2013; Li et al., 2012; Yu et al., 2007), provides a potential mechanism whereby stress fibres might not only direct the selfassembly of oriented ECM on cell surfaces by means of HSPGs; but may also regulate the bioavailability of TGF- $\beta$ (Saharinen et al., 1999) and hence control the rate at which ECM is synthesised and deposited between cell sheets (Chaudhry et al., 2007; Hayes and Ralphs, 2011; Massam-Wu et al., 2010).

Previous studies have shown that both glypicans- 6 and -3 are broadly expressed by a number of foetal tissues including disc during early development (Iglesias et al., 2008; Veugelers et al., 1999). Here, we show that glypican-6 is strongly associated with the development, 
growth and aging of both the disc and vertebral bodies of the spine. The strong expression of glypican- 6 by chondrocytes of the vertebral cartilages highlight established roles for this HSPG in chondrogenesis and endochondral ossification (Campos-Xavier et al., 2009). The spatio-temporal expression patterns of this HSPG within the constituent disc tissues also suggest roles in their ontogeny. The glypicans can interact with a wide range of ECM signalling components, including Indian hedgehog, bFGF, BMP and members of the canonical Wnt pathway (Filmus and Capurro, 2014). All of these signalling molecules play significant roles in IVD development and growth (Choi and Harfe, 2011; DiPaola et al., 2005; Dubrulle et al., 2001; Ellman et al., 2013; Kondo et al., 2011; Sivakamasundari and Lufkin, 2012). The glypicans, like the syndecans, can also bind fibronectin and collagen by means of their HS chains (Tumova et al., 2000), and may explain their overlapping expression patterns within the annulus, which is particularly striking at 4 months.

The HS expression patterns, after labelling with antibodies towards native HS (mAb 10E4) and the HS stub neoepitope (mAb 3G10) were broadly similar within the disc tissues throughout development; however, the HS stub appeared more prominent within the foetal nucleus pulposus. These epitopes can be differentially expressed in a number of developing tissues from different species and may be associated with a range of HSPGs (David et al., 1992; Melrose et al., 2012; van den Born et al., 2005). Previous studies of foetal human spine (Shu et al., 2013b) have shown that the 3 G10 HS stub epitope shows a similar expression pattern to that of perlecan, suggestive of their association. The broad overlapping expression patterns of glypican-6 with both the 10E4 and 3G10 HS epitopes observed here indicates that this PG may be variously sulphated with HS in the developing spinal tissues. Furthermore, whilst syndecan-4 expression correlated closely with the HS expression patterns in adult disc tissues, the weak correlation observed at foetal stages suggests that this PG may carry more CS substitutions during early development. This is consistent with previous observations in disc (Hayes et al., 2001; Hayes et al., 2011a) and underlines the potential for a broad repertoire of signalling pathways within the developmental spine.

An important property of the glypican and syndecan HSPGs, which is central to their roles in signalling, is that their ectodomains can be shed from the cell surface into the surrounding ECM by the action of proteases (syndecans) or phospholipases (glypicans). This allows them to function as soluble biological effectors and regulate morphogen gradients within the extracellular environment through interaction with specific growth factors, cytokines and morphogens (Park et al., 2000) (Refer to Fig. 9). The shed ectodomains also enable cellular adhesion to the surrounding matrix through interaction with ECM proteins such as fibronectin (Tumova et al., 2000; Woods et al., 2000). This property could account for the overlapping expression patterns of these molecules within the ECM of inner annulus and vertebral growth plate observed at later developmental stages. The growth plate, in particular, is a key signalling centre rich in growth factors (e.g., FGFs) and morphogens (e.g., BMP2) that are interactive with the syndecan, glypican and perlecan HSPG families (Jiao et al., 2007; Lazarus et al., 2007; Smith et al., 2007).

Lastly, a conspicuous feature of aged IVDs was the presence of chondrocyte clusters at the margins of the nucleus pulposus. These are generally regarded as a feature of disc degeneration and attempted cellular repair (Johnson et al., 2001). The co-expression of glypican-6 and syndecan-4 within these clusters, together with the $3 \mathrm{G} 10 \mathrm{HS}$ stub neoepitope, suggests that these HSPGs may be involved in age-related disc degeneration and/or an attempted cellular repair response. This is supported by recent experimental studies (Wang et al., 2011, 2014) which show that syndecan-4 plays a key role in the pathogenesis of IVD degeneration by promoting aggrecan catabolism within the nucleus pulposus. The conspicuous absence of fibronectin label within these clusters is also consistent with chondrocyte dedifferentiation and attempted repair (Tavella et al., 1997).

An understanding of how cells organise and maintain complex, oriented extracellular matrices, such as the annulus fibrosus of the intervertebral disc, is essential if we are to improve existing strategies for connective tissue repair. The results of the present study indicate that HS and the cell surface HSPGs, syndecan-4 and glypican-6, play diverse functional roles in the development, growth and aging of the IVD and associated connective tissues of the spine. Furthermore, our study highlights a potentiallysignificant new role for syndecan-4 in the establishment and maintenance of the lamellar organisation of oriented ECM within the annulus fibrosus, which may have relevance to other highly organised connective tissues including tendon and cornea.

\section{Acknowledgements}

This research was supported by funding from Arthritis Research UK and the Cardiff School of Biosciences. Thanks to Derek Scarborough for expert histological assistance throughout. We wish to confirm that there are no known conflicts of interest associated with this publication and there has been no significant financial support for this work that could have influenced its outcome.

\section{References}

Alini M, Eisenstein SM, Ito K, Little C, Kettler AA, Masuda K, Melrose J, Ralphs J, Stokes I, Wilke HJ (2008) Are animal models useful for studying human disc disorders/degeneration? Eur Spine J 17: 2-19.

Asparuhova MB, Gelman L, Chiquet M (2009) Role of the actin cytoskeleton in tuning cellular responses to external mechanical stress. Scand J Med Sci Sports 19: 490-499.

Aszodi A, Chan D, Hunziker E, Bateman JF, Fassler $\mathrm{R}$ (1998) Collagen II is essential for the removal of the notochord and the formation of intervertebral discs. J Cell Biol 143: 1399-1412.

Baldwin AK, Cain SA, Lennon R, Godwin A, Merry CL, Kielty CM (2014) Epithelial-mesenchymal status 
influences how cells deposit fibrillin microfibrils. J Cell Sci 127: 158-171.

Banos CC, Thomas AH, Kuo CK (2008) Collagen fibrillogenesis in tendon development: current models and regulation of fibril assembly. Birth Defects Res C Embryo Today 84: 228-244.

Bass MD, Morgan MR, Humphries MJ (2007) Integrins and syndecan-4 make distinct, but critical, contributions to adhesion contact formation. Soft Matter 3: 372-376.

Bellin RM, Kubicek JD, Frigault MJ, Kamien AJ, Steward RL, Jr., Barnes HM, Digiacomo MB, Duncan LJ, Edgerly CK, Morse EM, Park CY, Fredberg JJ, Cheng CM, LeDuc PR (2009) Defining the role of syndecan-4 in mechanotransduction using surface-modification approaches. Proc Natl Acad Sci USA 106: 22102-22107.

Bernfield M, Sanderson RD (1990) Syndecan, a developmentally regulated cell surface proteoglycan that binds extracellular matrix and growth factors. Philos Trans R Soc Lond B Biol Sci 327: 171-186.

Birk DE, Trelstad RL(1984) Extracellular compartments in matrix morphogenesis: collagen fibril, bundle, and lamellar formation by corneal fibroblasts. J Cell Biol 99: 2024-2033.

Birk DE, Trelstad RL(1986) Extracellular compartments in tendon morphogenesis: collagen fibril, bundle, and macroaggregate formation. J Cell Biol 103: 231-240.

Brooks R, Williamson R, Bass M (2012) Syndecan-4 independently regulates multiple small GTPases to promote fibroblast migration during wound healing. Small GTPases 3: 73-79.

Cain SA, Baldwin AK, Mahalingam Y, Raynal B, Jowitt TA, Shuttleworth CA, Couchman JR, Kielty CM (2008) Heparan sulfate regulates fibrillin-1 N- and C-terminal interactions. J Biol Chem 283: 27017-27027.

Campos-Xavier AB, Martinet D, Bateman J, Belluoccio D, Rowley L, Tan TY, Baxova A, Gustavson KH, Borochowitz ZU, Innes AM, Unger S, Beckmann JS, Mittaz L, Ballhausen D, Superti-Furga A, Savarirayan R, Bonafe L (2009) Mutations in the heparan-sulfate proteoglycan glypican 6 (GPC6) impair endochondral ossification and cause recessive omodysplasia. Am J Hum Genet 84: 760-770.

Canty EG, Lu Y, Meadows RS, Shaw MK, Holmes DF, Kadler KE (2004) Coalignment of plasma membrane channels and protrusions (fibripositors) specifies the parallelism of tendon. J Cell Biol 165: 553-563.

Carey DJ (1997) Syndecans: multifunctional cellsurface co-receptors. Biochem J 327: 1-16.

Chaudhry SS, Cain SA, Morgan A, Dallas SL, Shuttleworth CA, Kielty CM (2007) Fibrillin-1 regulates the bioavailability of TGFbeta1. J Cell Biol 176: 355-367.

Chiquet M, Renedo AS, Huber F, Fluck M (2003) How do fibroblasts translate mechanical signals into changes in extracellular matrix production? Matrix Biol 22: 73-80.

Chiquet M, Gelman L, Lutz R, Maier S (2009) From mechanotransduction to extracellular matrix gene expression in fibroblasts. Biochim Biophys Acta 1793: 911-920.

Choi KS, Harfe BD (2011) Hedgehog signaling is required for formation of the notochord sheath and patterning of nuclei pulposi within the intervertebral discs. Proc Natl Acad Sci USA 108: 9484-9489.

Choi Y, Chung H, Jung H, Couchman JR, Oh ES (2011) Syndecans as cell surface receptors: Unique structure equates with functional diversity. Matrix Biol 30: 93-99.

Couchman JR, Woods A (1999) Syndecan-4 and integrins: combinatorial signaling in cell adhesion. J Cell Sci 112: 3415-3420.

David G, Bai XM, Van der Schueren B, Cassiman JJ, Van den Berghe H (1992) Developmental changes in heparan sulfate expression: in situ detection with mAbs. J Cell Biol 119: 961-975.

Deepa SS, Yamada S, Zako M, Goldberger O, Sugahara K (2004) Chondroitin sulfate chains on syndecan-1 and syndecan-4 from normal murine mammary gland epithelial cells are structurally and functionally distinct and cooperate with heparan sulfate chains to bind growth factors. A novel function to control binding of midkine, pleiotrophin, and basic fibroblast growth factor. J Biol Chem 279: 3736837376.

DePina AS, Langford GM (1999) Vesicle transport: the role of actin filaments and myosin motors. Microsc Res Tech 47: 93-106.

DiPaola CP, Farmer JC, Manova K, Niswander LA (2005) Molecular signaling in intervertebral disk development. J Orthop Res 23: 1112-1119.

Dubrulle J, McGrew MJ, Pourquie O (2001) FGF signaling controls somite boundary position and regulates segmentation clock control of spatiotemporal Hox gene activation. Cell 106: 219-232.

Dzamba BJ, Wu H, Jaenisch R, Peters DM (1993) Fibronectin binding site in type I collagen regulates fibronectin fibril formation. J Cell Biol 121: 1165-1172.

Echtermeyer F, Baciu PC, Saoncella S, Ge Y, Goetinck $\mathrm{PF}$ (1999) Syndecan-4 core protein is sufficient for the assembly of focal adhesions and actin stress fibers. J Cell Sci 112: 3433-3441.

Elfenbein A, Simons M (2013) Syndecan-4 signaling at a glance. J Cell Sci 126: 3799-3804.

Ellman MB, Yan D, Ahmadinia K, Chen D, An HS, Im HJ (2013) Fibroblast growth factor control of cartilage homeostasis. J Cell Biochem 114: 735-742.

Fico A, Maina F, Dono R (2011) Fine-tuning of cell signaling by glypicans. Cell Mol Life Sci 68: 923-929.

Filmus J, Capurro M (2014) The role of glypicans in Hedgehog signaling. Matrix Biol 35: 248-252.

Filmus J, Capurro M, Rast J (2008) Glypicans. Genome Biol 9: 224.

Hashizume H (1980) Three-dimensional architecture and development of lumber intervertebral discs. Acta Med Okayama 34: 301-314.

Hayes AJ, Ralphs JR (2011) The response of foetal annulus fibrosus cells to growth factors: modulation of matrix synthesis by TGF-beta1 and IGF-1. Histochem Cell Biol 136: 163-175.

Hayes AJ, Benjamin M, Ralphs JR (1999) Role of actin stress fibres in the development of the intervertebral disc: cytoskeletal control of extracellular matrix assembly. Dev Dyn 215: 179-189. 
Hayes AJ, Benjamin M, Ralphs JR (2001) Extracellular matrix in development of the intervertebral disc. Matrix Biol 20: 107-121.

Hayes AJ, Hughes CE, Ralphs JR, Caterson B (2011a) Chondroitin sulphate sulphation motif expression in the ontogeny of the intervertebral disc. Eur Cell Mater 21: $1-14$.

Hayes AJ, Isaacs MD, Hughes C, Caterson B, Ralphs JR (2011b) Collagen fibrillogenesis in the development of the annulus fibrosus of the intervertebral disc. Eur Cell Mater 22: 226-241.

Hayes AJ, Smith SM, Gibson MA, Melrose J (2011c) Comparative immunolocalization of the elastin fiberassociated proteins fibrillin-1, LTBP-2, and MAGP-1 with components of the collagenous and proteoglycan matrix of the fetal human intervertebral disc. Spine 36: E1365-1372.

Hayes AJ, Smith SM, Melrose J (2013) Comparative immunolocalisation of fibrillin-1 and perlecan in the human foetal, and HS-deficient hspg2 exon 3 null mutant mouse intervertebral disc. Histochem Cell Biol 139: 1-11.

Hayes AJ, Gibson MA, Shu C, Melrose J (2014) Confocal microscopy demonstrates association of LTBP-2 in fibrillin-1 microfibrils and colocalisation with perlecan in the disc cell pericellular matrix. Tissue Cell 46: 185-197.

Hickey DS, Hukins DW (1980) X-ray diffraction studies of the arrangement of collagenous fibres in human fetal intervertebral disc. J Anat 131: 81-90.

Horowitz A, Tkachenko E, Simons M (2002) Fibroblast growth factor-specific modulation of cellular response by syndecan-4. J Cell Biol 157: 715-725.

Humzah MD, Soames RW (1988) Human intervertebral disc: structure and function. Anat Rec 220: 337-356.

Iglesias BV, Centeno G, Pascuccelli H, Ward F, Peters MG, Filmus J, Puricelli L, de Kier Joffe EB (2008) Expression pattern of glypican-3 (GPC3) during human embryonic and fetal development. Histol Histopathol 23: 1333-1340.

Jiao X, Billings PC, O’Connell MP, Kaplan FS, Shore EM, Glaser DL (2007) Heparan sulfate proteoglycans (HSPGs) modulate BMP2 osteogenic bioactivity in $\mathrm{C} 2 \mathrm{C} 12$ cells. J Biol Chem 282: 1080-1086.

Jin H, Shen J, Wang B, Wang M, Shu B, Chen D (2011) TGF-beta signaling plays an essential role in the growth and maintenance of intervertebral disc tissue. FEBS Lett 585: 1209-1215.

Johnson WE, Eisenstein SM, Roberts S (2001) Cell cluster formation in degenerate lumbar intervertebral discs is associated with increased disc cell proliferation. Connect Tissue Res 42: 197-207.

Kadler KE, Hill A, Canty-Laird EG (2008) Collagen fibrillogenesis: fibronectin, integrins, and minor collagens as organizers and nucleators. Curr Opin Cell Biol 20: 495 501.

Kinsey R, Williamson MR, Chaudhry S, Mellody KT, McGovern A, Takahashi S, Shuttleworth CA, Kielty CM (2008) Fibrillin-1 microfibril deposition is dependent on fibronectin assembly. J Cell Sci 121: 2696-2704.

Kondo N, Yuasa T, Shimono K, Tung W, Okabe T, Yasuhara R, Pacifici M, Zhang Y, Iwamoto M, EnomotoIwamoto M (2011) Intervertebral disc development is regulated by Wnt/beta-catenin signaling. Spine 36: E513518.

Lazarus JE, Hegde A, Andrade AC, Nilsson O, Baron J (2007) Fibroblast growth factor expression in the postnatal growth plate. Bone 40: 577-586.

Li L, Chaikof EL (2002) Mechanical stress regulates syndecan-4 expression and redistribution in vascular smooth muscle cells. Arterioscler Thromb Vasc Biol 22: 61-68.

Li B, Urban JP, Yu J (2012) The distribution of fibrillin-2 and LTBP-2, and their co-localisation with fibrillin-1 in adult bovine tail disc. J Anat 220: 164-172.

Lin X (2004) Functions of heparan sulfate proteoglycans in cell signaling during development. Development 131: 6009-6021.

Longley RL, Woods A, Fleetwood A, Cowlinmg GJ, Gallagher JT, Couchman JR (1999) Control of morphology, cytoskeleton and migration by syndecan-4. J Cell Sci 112: 3421-3431.

Lopes CC, Dietrich CP, Nader HB (2006) Specific structural features of syndecans and heparan sulfate chains are needed for cell signaling. Braz J Med Biol Res 39: 157-167.

Mao Y, Schwarzbauer JE (2005) Fibronectin fibrillogenesis, a cell-mediated matrix assembly process. Matrix Biol 24: 389-399.

Massam-Wu T, Chiu M, Choudhury R, Chaudhry SS, Baldwin AK, McGovern A, Baldock C, Shuttleworth CA, Kielty CM (2010) Assembly of fibrillin microfibrils governs extracellular deposition of latent TGF beta. J Cell Sci 123: 3006-3018.

McDonald JA, Kelley DG, Broekelmann TJ (1982) Role of fibronectin in collagen deposition: Fab' to the gelatinbinding domain of fibronectin inhibits both fibronectin and collagen organization in fibroblast extracellular matrix. J Cell Biol 92: 485-492.

Melrose J, Smith S, Ghosh P, Whitelock J (2003) Perlecan, the multidomain heparan sulfate proteoglycan of basement membranes, is also a prominent component of the cartilaginous primordia in the developing human fetal spine. J Histochem Cytochem 51: 1331-1341.

Melrose J, Hayes AJ, Whitelock JM, Little CB (2008) Perlecan, the "jack of all trades" proteoglycan of cartilaginous weight-bearing connective tissues. Bioessays 30: 457-469.

Melrose J, Isaacs MD, Smith SM, Hughes CE, Little CB, Caterson B, Hayes AJ (2012) Chondroitin sulphate and heparan sulphate sulphation motifs and their proteoglycans are involved in articular cartilage formation during human foetal knee joint development. Histochem Cell Biol 138: 461-475.

Morgan MR, Humphries MJ, Bass MD (2007) Synergistic control of cell adhesion by integrins and syndecans. Nat Rev Mol Cell Biol 8: 957-969.

Nosikova YS, Santerre JP, Grynpas M, Gibson G, Kandel RA (2012) Characterization of the annulus fibrosusvertebral body interface: identification of new structural features. J Anat 221: 577-589.

Okina E, Grossi A, Gopal S, Multhaupt HA, Couchman JR (2012) Alpha-actinin interactions with syndecan-4 
are integral to fibroblast-matrix adhesion and regulate cytoskeletal architecture. Int J Biochem Cell Biol 44: 2161-2174.

Park PW, Reizes O, Bernfield M (2000) Cell surface heparan sulfate proteoglycans: selective regulators of ligand-receptor encounters. J Biol Chem 275: 29923 29926.

Peacock A (1951) Observations on the prenatal development of the intervertebral disc in man. J Anat 85: 260-274.

Pellegrin S, Mellor H (2007) Actin stress fibres. J Cell Sci 120: 3491-3499.

Pompe T, Renner L, Werner C (2005) Nanoscale features of fibronectin fibrillogenesis depend on proteinsubstrate interaction and cytoskeleton structure. Biophys J 88: 527-534.

Rufai A, Benjamin M, Ralphs JR (1995) The development of fibrocartilage in the rat intervertebral disc. Anat Embryol 192: 53-62.

Sabatier L, Chen D, Fagotto-Kaufmann C, Hubmacher D, McKee MD, Annis DS, Mosher DF, Reinhardt DP (2009) Fibrillin assembly requires fibronectin. Mol Biol Cell 20: 846-858.

Sabatier L, Djokic J, Hubmacher D, Dzafik D, Nelea V, Reinhardt DP (2014) Heparin/heparan sulfate controls fibrillin-1, -2 and -3 self-interactions in microfibril assembly. FEBS Lett 588: 2890-2897.

Saharinen J, Hyytiainen M, Taipale J, Keski-Oja J (1999) Latent transforming growth factor-beta binding proteins (LTBPs) - structural extracellular matrix proteins for targeting TGF-beta action. Cytokine Growth Factor Rev 10: 99-117.

Saoncella S, Echtermeyer F, Denhez F, Nowlen JK, Mosher DF, Robinson SD, Hynes RO, Goetinck PF (1999) Syndecan-4 signals cooperatively with integrins in a Rhodependent manner in the assembly of focal adhesions and actin stress fibers. Proc Natl Acad Sci USA 96: 2805-2810.

Sevilla CA, Dalecki D, Hocking DC (2013) Regional fibronectin and collagen fibril co-assembly directs cell proliferation and microtissue morphology. PloS One 8: e77316.

Shu C, Hughes C, Smith SM, Smith MM, Hayes A, Caterson B, Little CB, Melrose J (2013a) The ovine newborn and human foetal intervertebral disc contain perlecan and aggrecan variably substituted with native 7D4 CS sulphation motif: spatiotemporal immunolocalisation and co-distribution with Notch-1 in the human foetal disc. Glycoconj J 30: 717-725.

Shu C, Smith SS, Little CB, Melrose J (2013b) Comparative immunolocalisation of perlecan, heparan sulphate, fibroblast growth factor-18, and fibroblast growth factor receptor-3 and their prospective roles in chondrogenic and osteogenic development of the human foetal spine. Eur Spine J 22: 1774-1784.

Shworak NW, Shirakawa M, Mulligan RC, Rosenberg RD(1994) Characterization of ryudocan glycosaminoglycan acceptor sites. J Biol Chem 269: 21204-21214.

Sivakamasundari V, Lufkin T (2012) Bridging the gap: Understanding embryonic intervertebral disc development. Cell Dev Biol 1: 103.
Sivan SS, Hayes AJ, Wachtel E, Caterson B, Merkher Y, Maroudas A, Brown S, Roberts S (2013) Biochemical composition and turnover of the extracellular matrix of the normal and degenerate intervertebral disc. Eur Spine J 23 Suppl 3: S344-353.

Smith SM, West LA, Govindraj P, Zhang X, Ornitz DM, Hassell JR (2007) Heparan and chondroitin sulfate on growth plate perlecan mediate binding and delivery of FGF-2 to FGF receptors. Matrix Biol 26: 175-184.

Tavella S, Bellese G, Castagnola P, Martin I, Piccini D, Doliana R, Colombatti A, Cancedda R, Tacchetti C (1997) Regulated expression of fibronectin, laminin and related integrin receptors during the early chondrocyte differentiation. J Cell Sci 110: 2261-2270.

Tumova S, Woods A, Couchman JR (2000) Heparan sulfate chains from glypican and syndecans bind the Hep II domain of fibronectin similarly despite minor structural differences. J Biol Chem 275: 9410-9417.

van den Born J, Salmivirta K, Henttinen T, Ostman N, Ishimaru T, Miyaura S, Yoshida K, Salmivirta M (2005) Novel heparan sulfate structures revealed by monoclonal antibodies. J Biol Chem 280: 20516-20523.

Veugelers M, De Cat B, Ceulemans H, Bruystens AM, Coomans C, Durr J, Vermeesch J, Marynen P, David G (1999) Glypican-6, a new member of the glypican family of cell surface heparan sulfate proteoglycans. J Biol Chem 274: 26968-26977.

Wang JH, Jia F, Gilbert TW, Woo SL (2003) Cell orientation determines the alignment of cell-produced collagenous matrix. J Biomech 36: 97-102.

Wang J, Markova D, Anderson DG, Zheng Z, Shapiro IM, Risbud MV (2011) TNF-alpha and IL-1beta promote a disintegrin-like and metalloprotease with thrombospondin type I motif-5-mediated aggrecan degradation through syndecan-4 in intervertebral disc. J Biol Chem 286: 3973839749.

Wang X, Wang H, Yang H, Li J, Cai Q, Shapiro IM, Risbud MV (2014) Tumor necrosis factor-alpha- and interleukin-1beta-dependent matrix metalloproteinase-3 expression in nucleus pulposus cells requires cooperative signaling via syndecan 4 and mitogen-activated protein kinase-NF-kappaB axis: implications in inflammatory disc disease. Am J Pathol 184: 2560-2572.

Wilcox-Adelman SA, Denhez F, Goetinck PF (2002) Syndecan-4 modulates focal adhesion kinase phosphorylation. J Biol Chem 277: 32970-32977.

Woods A, Couchman JR (1994) Syndecan 4 heparan sulfate proteoglycan is a selectively enriched and widespread focal adhesion component. Mol Biol Cell 5: 183-192.

Woods A, Couchman JR (2001) Syndecan-4 and focal adhesion function. Curr Opin Cell Biol 13: 578-583.

Woods A, Longley RL, Tumova S, Couchman JR (2000) Syndecan-4 binding to the high affinity heparinbinding domain of fibronectin drives focal adhesion formation in fibroblasts. Arch Biochem Biophys 374: 66-72.

Wu C, Bauer JS, Juliano RL, McDonald JA (1993) The alpha 5 beta 1 integrin fibronectin receptor, but not the alpha 5 cytoplasmic domain, functions in an early and 
essential step in fibronectin matrix assembly. J Biol Chem 268: 21883-21888.

Yan D, Lin X (2009) Shaping morphogen gradients by proteoglycans. Cold Spring Harb Perspect Biol 1: a002493.

Young RD, Knupp C, Pinali C, Png KM, Ralphs JR, Bushby AJ, Starborg T, Kadler KE, Quantock AJ (2014) Three-dimensional aspects of matrix assembly by cells in the developing cornea. Proc Natl Acad Sci USA 111: 687-692.

Yu J, Tirlapur U, Fairbank J, Handford P, Roberts S, Winlove CP, Cui Z, Urban J (2007) Microfibrils, elastin fibres and collagen fibres in the human intervertebral disc and bovine tail disc. J Anat 210: 460-471.

Zhang G, Young BB, Ezura Y, Favata M, Soslowsky LJ, Chakravarti S, Birk DE (2005) Development of tendon structure and function: regulation of collagen fibrillogenesis. J Musculoskelet Neuronal Interact 5: 5-21.

Zilberberg L, Todorovic V, Dabovic B, Horiguchi M, Courousse T, Sakai LY, Rifkin DB (2012) Specificity of latent TGF-beta binding protein (LTBP) incorporation into matrix: role of fibrillins and fibronectin. J Cell Physiol 227: 3828-3836.

\section{Discussion with Reviewers}

Reviewer I: What is the clinical relevance of these studies? Authors: These studies aim to understand the basic developmental mechanisms underlying the formation of the annulus fibrosus of the disc - a complex, highly-oriented musculoskeletal connective tissue. An understanding of the cellular mechanisms involved in its formation, as well as having broad relevance to other oriented connective tissues, e.g., tendon and cornea, has clinical relevance to the fields of tissue engineering and repair. Implicitly, if we understand how the tissues are 'put together' in vivo, we will be better placed to develop ex vivo tissue engineeringbased strategies aimed at repairing or replacing these tissues when they are damaged or diseased.

Reviewer II: The rat IVD is much smaller than that of a human and experiences different mechanical and nutritional pressures. Could these differences lead to variations in $\mathrm{AF}$ formation between species?
Authors: The developmental sequence that gives rise to the constituent disc tissues during foetal development (and by extension the underlying histogenetic mechanisms) appear highly conserved between rat and human. The rat, being much smaller than the human (as well as being quadrupedal) might, as you suggest, experience entirely different mechanical and nutritional pressures during postnatal development and growth and these differences could indeed lead to variations in tissue composition and morphology between species. Due to our bipedal stance, it is often assumed that our lumbar spines experience much larger mechanical loads than those experienced by quadrupeds. However, this may not necessarily be the case since muscle contraction and tension of ligaments also adds significantly to the loads acting upon the spine. Furthermore, the surface area of the discs upon which this load is acting in rats would be much smaller than in humans, thus the intradiscal pressures of both species might actually be quite similar.

Reviewer II: Might the authors consider the future use of a conditional knockout mouse as a means to provide direct evidence for syndecan-4 in AF formation?

Authors: Yes, this is something that we are currently looking into. Syndecan-4 deficiency has been shown to impair focal adhesion formation only under restricted conditions (Ishiguro et al., 2000) due to functional compensation by other syndecan family members; thus we may not necessarily see a phenotype within the discs of syndecan 4 deficient animals. It may be necessary, therefore, to use a double knockout model, whereby both syndecan 4 and syndecan 1, for example, have been conditionally deleted.

\section{Additional Reference}

Ishiguro K, Kadomatsu K, Kojima T, Muramatsu H, Tsuzuki S, Nakamura E, Kusugami K, Saito H, Muramatsu $\mathrm{T}$ (2000) Syndecan-4 deficiency impairs focal adhesion formation only under restricted conditions. J Biol Chem 275: 5249-5252.

Editor's Note: Scientific Editor in charge of the paper: Brian Johnstone. 